San Jose State University

SJSU ScholarWorks

Doctoral Projects

Master's Theses and Graduate Research

Spring 5-2015

\title{
Pain Management at End of Life When There is a Co-Occurrence of Substance Use Disorder: A Qualitative Metasynthesis
}

\author{
Kristina Olfson \\ Northern California Consortium, Doctor of Nursing Practice Program, California State University, Fresno \\ and San José State University
}

Follow this and additional works at: https://scholarworks.sjsu.edu/etd_doctoral

Part of the Other Nursing Commons

\section{Recommended Citation}

Olfson, Kristina, "Pain Management at End of Life When There is a Co-Occurrence of Substance Use Disorder: A Qualitative Metasynthesis" (2015). Doctoral Projects. 20.

DOI: https://doi.org/10.31979/etd.bvh8-gfkq

https://scholarworks.sjsu.edu/etd_doctoral/20

This Doctoral Project is brought to you for free and open access by the Master's Theses and Graduate Research at SJSU ScholarWorks. It has been accepted for inclusion in Doctoral Projects by an authorized administrator of SJSU ScholarWorks. For more information, please contact scholarworks@sjsu.edu. 
Pain Management at End of Life when there is a Co-Occurrence of

Substance Use Disorder: a Qualitative Metasynthesis

Kristina Olfson, DNP, RN, FNP-BC

California State University, Northern Consortium

Doctor of Nursing Practice

School of Nursing

May 1, 2015 


\section{Acknowledgements}

"In normal life we hardly realize how much more we receive than we give, and life cannot be rich without such gratitude. It is so easy to overestimate the importance of our own achievements compared with what we owe to the help of others.” Dietrich Bonhoeffer

I would like to express my deepest gratitude to Jim, my dear husband and best friend for his love, encouragement, clear thinking and foot rubs - and to my three amazing daughters, Kirsten, Haleigh, and Olivia for their patience, support, love and tech savvy. To my parents Donna and Swede - thank you for your encouragement, love and for teaching me the value of persistence. Kari, Dee, Susi, Tina, Michael, Wendy, Tim and Don- Thank you for your enthusiastic support, love and many kindnesses. Hunter, Brie, Meredith, RJ, GiGi, Connor, Jarrett, Maddie, Sebastian - I am a lucky auntie that you are in my life. And to my cousins, aunts and uncle - I love you all. A special acknowledgement for my dear brother Erik John and my mother in law Joy as well as my two cousins who left this world too soon - you are in my heart every day.

For my wonderful friends near and far - thank you for letting me lean on you- Lorraine, Robert, Caroline, Dave, Christine, Lynn, Caron, Cori, Becky, Nancy, Cara Jean, Fay, Alan your understanding, technical assistance, encouraging words, and good humor has meant so much.

Dr. Susan McNiesh, my project chair and mentor - thank you for your sincere interest in this topic, for sharing your keen intelligence, and for the many hours of collaboration, guidance and calm and for providing a structure that has kept me focused. And to Dr. Virginia Kane and Dr. Canyon Steinzig - my project committee members thank you so much for your willingness to participate, your support, encouragement and contributions. I want to especially thank my advisor, Dr. Sylvia Miller and the professors of the Northern Consortium for building this program and working so diligently towards its continued development. Thank you also to my remarkable DNP cohort - your talent and expertise are only matched by your kindness and fun I can't imagine a greater group of nursing professionals to travel with on this path.

I could not have completed this process without the enthusiastic support of my incredible Colleagues at VNA Hospice, Carmel Hills Care Center, Pacific Grove Convalescent and Canterbury Woods - I am SO fortunate to work with such incredible professionals.

And thank you to Margo McCaffery - in our brief email conversation, your confirmation of the value of my project and the challenges of pain management in this patient population was tremendously encouraging and empowering.

And finally to my patients past and present - I am so grateful to have known you and to have learned so much from you. 


\section{Table of Contents}

Abstract $\quad 5$

$\begin{array}{ll}\text { Introduction } & 6\end{array}$

Substance Use Disorder $\quad 6$

Pain $\quad 8$

End of Life Care $\quad 10$

$\begin{array}{lr}\text { Purpose Statement } & 12\end{array}$

$\begin{array}{ll}\text { Theoretical Framework } & 13\end{array}$

$\begin{array}{ll}\text { Concepts } & 14\end{array}$

$\begin{array}{ll}\text { Definitions } & 14\end{array}$

$\begin{array}{ll}\text { Subjectivity of Pain } & 14\end{array}$

Pain Threshold $\quad 15$

Pain Tolerance $\quad 15$

Behavioral and Physiologic Responses $\quad 15$

$\begin{array}{ll}\text { Causes of Pain } & 15\end{array}$

$\begin{array}{ll}\text { Addiction } & 16\end{array}$

$\begin{array}{ll}\text { Physical Dependence } & 16\end{array}$

$\begin{array}{ll}\text { Physical Tolerance } & 16\end{array}$

$\begin{array}{ll}\text { Pseudo Addiction } & 16\end{array}$

$\begin{array}{ll}\text { Impact of Personal Bias } & 16\end{array}$

Additional Points 16

$\begin{array}{ll}\text { Applicability of Framework } & 17\end{array}$

$\begin{array}{ll}\text { Description of Relevant Literature } & 18\end{array}$

$\begin{array}{lr}\text { Methods } & 29\end{array}$

Project Design $\quad 30$

Investigative Techniques $\quad 31$

Phase I $\quad 31$

Phase II $\quad 32$

Phase III 33

Phase IV 34

Phase V 34

Rigor $\quad 34$

Human Subjects $\quad 34$

Discussion of Key Findings $\quad 35$

Key Finding \#1 Knowing the Patient 34

Key Finding \#2 Fear $\quad 37$

Key Finding \#4 Mutually Exclusive Behaviors $\quad 39$

Key Finding \#4 System Barriers $\quad 40$

Limitations

41

Recommendations for Practice $\quad 41$ 


\section{Table of Contents, cont'd}

Strategies for Care of The Individual with SUD and Pain at EOL

Identifying the Patient with History of SUD and Assessing Risk

Harm Reduction

Dissemination and Implementation

Personal Practice Change

Recommendations for Further Research

Conclusion

Appendix A

Taxonomy of Findings

Appendix B

Figure 1 Knowing the Patient

Figure 2 Elements of Good QOL

Figure 3 Barriers to Good QOL

Figure 4 Fear Perspectives

Figure 5 System Barriers

71

References 


\begin{abstract}
Pain management, end of life (EOL) care, and substance use disorder (SUD) are individually identified as National healthcare challenges and priorities. Despite 50 years of advances in the understanding of pain management, pain is still inconsistently assessed and undertreated in all populations, including those with life limiting illness. When a patient with a life limiting illness and history of SUD is encountered, pain management becomes further complicated. Effective pain management for all patients, regardless of coexisting complications, is an ethical obligation of health care providers. Given the lack of research into EOL pain management of patients with SUD, it is not surprising that such individuals have been identified as a vulnerable population at high risk for undertreatment of pain. Additionally, the physical, psychosocial/spiritual care of this population can be challenging and frustrating, and there are few studies to guide health professionals in any of these areas. In this qualitative metasynthesis, the findings were derived from collecting, analyzing, interpreting and synthesizing the qualitative literature from 2010 2015 on the phenomena. The findings of this project reaffirm that pain can only be a subjective experience, and there is no more reliable gauge of pain than the individual's subjective report. The findings demonstrate also that clinicians continue to struggle with this subjectivity. The overarching finding of this project is that the concept of "knowing the patient" becomes even more significant as the foundation of effective care in the EOL/ SUD patient population. The combination of the key findings of this project, recommendations concerning pain management in EOL SUD patients, along with expert clinical knowledge and experience of end of life interdisciplinary team members, can provide a roadmap for the care of this challenging patient population.
\end{abstract}


Pain Management at End of Life when there is a Co-Occurrence of Substance Use Disorder:

a Qualitative Metasynthesis

\section{Introduction}

\section{Substance Use Disorder (SUD)}

According to the Substance Abuse and Mental Health Services Administration's (SAMHSA) 2013 National Survey on Drug use and Health, approximately 24.6 million people age 12 and over in the U.S. were current illicit drug users/ and identified as having a substance use disorder (SUD) 136.9 million or $52.2 \%$ of individuals age 12 and over in the US were current users of alcohol; with approximately 60.1 million or $22.9 \%$ identifying as "binge" alcohol users and 16.5 million or $6.3 \%$ identified as "heavy" drinkers. SAMHSA estimates that 18 million of these alcohol users have alcohol use disorder (AUD). A number of studies have shown that alcohol use disorder may be present in up to $28 \%$ of cancer patients (Dev, et al., 2011). It is reasonable to assume that similar percentages of SUD (including AUD) will be found in the populations entering end of life care. Known negative health outcomes of substance use disorders include cancer, liver disease, trauma, respiratory disease, overdose, cardiovascular disease, HIV, STIs, teen pregnancy, fetal damage, motor vehicle accidents, homicide and suicide (Healthy People, 2020). Crime, domestic violence, financial and productivity loss, school failure, family system and community disturbance are some of the socioeconomic fallout of the disorder (Healthy People 2020).

The term "substance use disorder (SUD)" is the DSM-V amalgamated terminology and criteria for the previously separate diagnoses in the DSM-IV of "substance abuse" and "dependence". The criteria are very nearly similar with the exception of the removal of the 
DSM-IV "recurrent legal problems" criterion, and in DSM-V, the addition of the criterion of "craving" or "desire to use" a substance. Additionally, in order for there to be a diagnosis of SUD, the DSM-5 sets the threshold that 2 of the 11 diagnostic criteria must be met. The severity of the disorder is judged by how many of the SUD criteria are met.

Existing vulnerabilities as a result of ethnicity, race, poverty, mental and chronic illness are compounded by substance use disorder (Walley \& Roll, 2007). Caring for individuals with substance use disorders is challenging and can be frustrating for providers and family alike. Furthermore, according to Walley and Roll, approximately $45 \%$ of patients with substance use disorder do not believe that their primary care provider is aware of their problem; providers often fail to use screening tools, and often fail to refer for treatment. As a result, access to care and quality of care suffer. There is also documentation of mutual mistrust: providers may believe that the patient will use prescription drugs recreationally or sell them, and patients may expect rapid results from medications prescribed, have perceptions of mistreatment, or have other unrealistic expectations of their provider (Walley \& Roll, 2007).

Common pitfalls of clinicians in caring for those with substance use disorder include underdiagosing and undertreating the disorder, poor provider-patient relationships, belief that treatment success must mean abstinence, that relapse equals failure, and belief that addiction is a character or moral flaw (Walley \& Roll, 2007). According to Oliver et al. (2012) there are four major conceptual models of substance use disorder which frame treatment direction all of which may co-exist and overlap:

1. Moral/criminal model sees the individual as morally flawed and socially deviant with treatment aimed at punishment within the legal system. 
2. 12 step models of treatment see substance use disorders as related to spiritual crisis and isolation from one's own values. Individuals are encouraged to follow a lifelong community based, group approach to recovery and maintenance of sobriety.

3. Disease based model views substance use disorder as a chronic illness. There is a disorder of dopaminergic pathways affecting the impulse and decision making areas of the brain resulting in compulsive drug use behaviors.

4. Bio-psycho-social-spiritual model sees pain and addiction as parts of a continuum. Treatment is aimed at integrating and restoring an individual's "wholeness".

Stigmatizing the individual by using terms such as "drug seeking”, "junkie", "addict”, etc. interferes with development of a therapeutic relationship and must be avoided (Oliver, et al., 2012). The overarching successful approach to care of those with SUD may include emphasis on harm reduction (e.g. needle exchange programs) to decrease the public health and societal impact. Additionally, there should be consideration of an interdisciplinary team approach, as studies show that a combination of substance abuse counseling, social work, and psychiatry are most effective (Walley \& Roll, 2007).

\section{Pain}

Pain is a common symptom which affects quality of life, contributes to lengthier hospital stays, readmissions and emergency room visits (American Academy of Pain Medicine, n.d.). Assessing pain as a "fifth vital sign" was introduced by the American Pain Society (APS) in 1996. This approach has been part of the Veteran Administration's national pain management strategy since 1999, and has been accepted as standard practice in many other arenas. The Joint Commission on Accreditation of Health Care Organizations (JCAHO) pain management standards for pain assessment and management went into effect in 2001, requiring all healthcare 
providers to appropriately assess and manage pain, and to educate those patients suffering pain and their families (JCAHO, 2014). Commonly identified barriers to adequate pain management include fear of addiction, knowledge deficits regarding substance use disorders, knowledge deficits of pain management in those with a co-occurrence of substance use disorder, and pain management in general (Morgan \& White, 2009). Additionally, fear of hastening death is a barrier common to pain management in end of life care (Reynolds, et al., 2013).

The 2010 Affordable Care Act required the Institute of Medicine (IOM) of the National Academies to examine pain relief as a national health challenge and priority, and to make recommendations. In their report "Relieving Pain in America - a Blueprint for Transforming Prevention, Care, Education and Research" the IOM reports that chronic pain affects as many as 100 million adults in the US and costs as much as $\$ 635$ billion yearly in treatment and lost productivity. Their recommendations include development of a comprehensive strategy to better assess, treat and understand pain of all types, and to address the regulatory, legal, institutional, financial and geographic barriers that exist (IOM, 2011).

Effective pain management, particularly in life limiting illness is an ethical obligation of health care providers (Fine, 2007), and in fact, the Oncology Nursing Society's (ONS) "Position on Cancer Pain Management” points out that individuals with active or history of substance abuse are a population known to be at high risk for undertreatment for pain. Specifically, the ONS (2013) states: "all people with pain must be recognized, with special emphasis placed on the populations known to be at high risk for suboptimal pain management (i.e., children...people with a history of previous or active substance abuse...)". Further, the position of the American Society for Pain Management Nursing along with the International Nurses Society on Addictions (As cited in Oliver, et al., 2012) states: "patients with substance use disorders and pain have the 
right to be treated with dignity, respect, and the same quality of pain assessment and management as all other patients". Additionally, according to the American Society for Pain Management Nursing's (ASPMN) position statement on pain management at end of life (Reynolds, et al., 2013) nurses and other health professionals are mandated to alleviate suffering for every patient receiving end of life care. This mandate by the ASPMN also emphasizes the need for pain management at end of life for those individuals residing in long term care facilities, where there is high risk of undertreatment of pain, particularly in those with cognitive impairment.

\section{End of Life Care}

Challenges in quality end of life care include access to care, professional's education regarding end of life care and communication, along with ethical and legal debates (Giovanni, 2012). Additionally, there are regulatory barriers, symptom management barriers and for some health care professionals, both federal and state scope of practice barriers ( DuBois \& Reed, 2014). Care management of patients (and family) at end of life when there is a history of aberrant drug use can be a difficult and complex problem for hospice staff, and raises unique clinical and ethical dilemmas (Kirsh \& Smith, 2008). In the setting of substance abuse, a dying patient's pain control can be challenging, families may be chaotic and dysfunctional, and clinicians may not grasp the impact of addiction on the family unit (Kirsh \& Smith, 2008). There are some who may argue that if an individual has a life limiting illness, SUD should not be considered (Walsh \& Broglia, 2010). Hospice and palliative care clinicians may believe that efforts to address substance abuse are likely to fail and may even believe that decrease in substance use is depriving a patient of a source of pleasure. In reality, the chemically dependent patient's substance use may be itself a source of suffering and may appropriate care problem for 
hospice intervention (Kirsh \& Smith, 2008). Relief of both physical and existential pain, including the pain and chaos of a SUD must be included in the goals of end of life care.

Opioids are the gold standard for the treatment of cancer pain, but there is controversy over the use opioids for non cancer pain (Krashin, et al., 2012). Opioid use varies greatly throughout the world, with the most developed countries averaging $10 \mathrm{mg}$ morphine equivalent per capita per year and less than $0.01 \mathrm{mg}$ per capita per year in developing countries (Sullivan \& Howe, 2013). Escalation of prescription opioid sales was seen in the US, beginning in the mid 1980s, and this increase in use in the U.S. also drove an increase in global consumption. Significant events identified as contributing to the growth of use for pain management was a cornerstone article by Portenoy and Foley in 1986 on the use of opioids for chronic non cancer pain (CNCP) followed by the consensus statement in 1996 by the American Pain Society (APS) on opioid use for chronic pain treatment (Sullivan \& Howe, 2013). Subsequently, the passage in many states of the "Intractable Pain Acts" removed previous sanctions on long term/high dose opioid therapy. Further, the early 2000s was a time of aggressive opioid marketing by pharmaceutical companies. A notable example of this marketing blitz was Purdue Pharma's claims that Oxycontin was less addictive and less abusable than other pain medications. They later paid a \$634.5 million fine for this claim (Sullivan \& Howe, 2013).

Opioids are the mainstay of symptom management in end of life care - and their value is indisputable. However, there remains a love/hate relationship within the health care community and aberrant behaviors (dosage escalation, early refills, doctor and pharmacy shopping, lost or accidently destroyed medications and prescriptions, and frankly illegal activity) cannot be ignored (Krashin, et al., 2012). In caring for patients with co-occurring pain and SUD, Krashin, et al. (2012) advise that it is not enough to diagnose the pain condition, substance use and 
psychiatric conditions: there must be thorough assessment of the individual's total psychosocial circumstances - including vulnerabilities, strengths and stressors. Patients may have multiple risk factors for aberrant behaviors around opioid use - including substance use disorder, pseudoaddiction, confusional states, miscommunication, personality disorders and other mental disorders (Krashin, et al., 2012).

\section{Purpose Statement}

Individually, end of life care, substance use disorders, and pain management are identified as national healthcare challenges and priorities, and improving the value of healthcare while reducing cost must be achieved (Fletcher \& Panke, 2012). Although over the past 40 years, there have been advances in the understanding of pain management, pain is still inconsistently assessed and undertreated in patients with life limiting illness, barriers remain much the same, and there is real concern and discomfort in health care professionals regarding how to assess and manage pain especially in the setting of chronic opioid use and when there is fear of substance use disorder (Gardiner, et al., 2012). When asked, clinicians "know" that "pain is what the person says it is and exists whenever he or she says it does" (McCaffrey, 1968 as cited in Pasero \& McCaffery, 2011, p.21), but often do not "believe" the patient's subjective report of pain. Clinicians may be concerned about drug diversion, "spilled" or otherwise missing medication, consistent reports of pain as 10/10 despite escalating doses of pain medication, and breakthrough dosing "on the clock". Patients may feel "judged", and may be unwilling to disclose. Addiction is a disease with many "secrets" and half truths, and can color the interactions in end of life pain management and care

McCaffery’s 1968 definition of pain was a simple and revolutionary truth. However, in addition to accepting the patient's subjective report of pain, the clinician must take into account 
the patient and patient system as a whole, otherwise risk problems in clinical decision making (Pesut \& McDonald, 2007). Perception of pain is a complex phenomena with both physical and psychological components contributing to the pain experience (Smith, et al, 2007).

There is limited information in the literature regarding pain management in patients at end of life with a co-occurrence or history of substance use disorder. Initial searches of key terms " substance abuse and hospice/end of life care", "substance abuse and pain management and hospice and end of life care", "pain management and hospice" and "pain management and substance abuse" identify gaps in the literature, the challenges in providing care but no consensus as to how to care for this special population at end of life. It is the intent of this project to evaluate the literature by means of qualitative metasynthesis, summarize and interpret the evidence, and make recommendations for practice.

\section{Theoretical Framework}

Margo McCaffery has set the bar for pain assessment and management and her revolutionary concepts have remained relevant and a gold standard in the compassionate care of individuals with pain. McCaffery (1990) remarks that when she was in graduate school in the 1960s and wanting to write about pain, she was told by her professor to choose a different topic because too little was known. Indeed, when one searches the CINAHL data base with the term “pain” from 1900-1959, 67 articles are identified; from 1960-1999, 24,459 articles are identified; and then from 2000-2015, 144,469 articles. While tremendous strides have been made since McCaffery first introduced the concept "pain is whatever the experiencing person says it is, existing whenever he says it does" (McCaffery, 1968 as stated in McCaffery,Herr and Pasero, 
2011 p. 21) in 1968, pain is still often undertreated and many of the barriers to adequate pain management identified early on persist today.

McCaffery's concepts provide a practice framework through which to address the population in this study: "In the end I think you will realize that [this patient population] you selected to study has two problems at a minimum, and as a nurse it is your responsibility to try to help the patient with both. And realize we often fail at both, but we try not to give up. But just as we cannot force pain relief on a patient who refuses it, we cannot force recovery on a patient who does not want it or know he needs it (M. McCaffery, personal communication, March 23, 2015)".

\section{Concepts}

McCaffery has advocated for the use of guidelines "formulated by committees of pain specialists" as well as encouragement for health professionals to accept that the sensation of pain is completely subjective. She continues to advocate that fears around addiction and misuse can be decreased with better understanding of the definitions of addiction, tolerance and physical dependence. Historically, there has been lack of consensus on the terminology used by health care, law enforcement, regulatory and reimbursement organizations to describe the terms around SUD, substance use and "addiction". The following definitions from McCaffery et al. (2011) help to clarify "misconceptions that hamper assessment and treatment of patients who report pain" (p.20).

\section{Definitions}

Subjectivity of Pain. The sensation of pain is personal and subjective and includes the impact of an individual's culture and ethnicity (McCaffery, et al., 2011), and to date there have been no 
more reliable gauges of pain than what the patient says. The "opinions" of the health care professionals and family members of the patient, as well as measures such as vital signs are not more valid than the patient's report of pain. It is the responsibility of the health care professional to accept the report of pain at face value and take action based on the self report, whether or not they personally "believe" the patient's report (McCaffery, et al., 2011).

Pain Threshold. The intensity, duration and character of pain is perceived differently from one individual to another (McCaffery, et al., 2011).

Pain Tolerance. Tolerance is the maximum intensity or duration of pain that is acceptable to an individual (McCaffery,et al. 2011).

Behavioral and Physiologic Responses. While the "Acute Pain Model" as described by McCaffery et al. (2011) states that there will often be objective physical signs of pain tachycardia, hypertension, grimacing, frowning, crying, bracing, limping, etc., these are often short lived and there will be behavioral adaptation or other suppression of pain behavior. Simultaneously, an individual with pain may alter their behavior to meet the expectations of what a person in pain "should" look like. This is often interpreted by a clinician as manipulative but it may be brought about in the first place by the clinician or societal expectations of how the person in pain should behave (McCaffery,et al.2011). The sleeping patient is also an individual who may be mistakenly identified as having no pain (McCaffery, et al., 2011).

Causes of Pain. Cause of pain may or may not be able to be determined. Available assessment tools may not tease out the problem, but just because a cause cannot be established, it does not mean that the patient does not have pain (McCaffery, et al., 2011). Approximately $50 \%$ of 
patients with unrelenting pain may also have depression or anxiety disorder, and considerable interference with quality of life (McCaffery, et al., 2011).

Addiction. Addiction may be defined as a chronic biologic neurologic disease with environmental, psychosocial and genetic components. Behaviors may include compulsive use of a substance, impaired control craving, and continued use of the substance despite negative consequences (McCaffery, et al., 2011).

Physical Dependence. This is a normal physiologic response to use of opiates and is a state of adaptation that results in symptoms of withdrawal if the agent is stopped abruptly (McCaffery, et al., 2011).

Physical Tolerance. This is a normal physiologic response to use of opiates resulting in decreased analgesia, decreased sedation and/or decreased respiratory depression. If pain is stable, this ordinarily results in stable doses, and the need for increased dosing may be primarily related to disease progression, not tolerance (McCaffery, et al., 2011).

Pseudo Addiction. When a patient's pain is under treated, they may behave in a way that is consistent with addiction (e.g. deception, illicit drug use, clock watching, escalating demands, etc.), however behaviors resolve once pain is treated effectively (McCaffery,et al., 2011).

Impact of Personal Bias. Physical appearance, gender, age, race/culture, personal pain experiences, “ “irresponsible"” lifestyle all may impact a clinician's beliefs about an individual's report of pain, and lead to inadequate pain management. It is incumbent on all clinicians to identify and strive to overcome their biases (McCaffery, et al., 2011).

\section{Additional points}


Opioids are unlikely to hasten death in an opioid tolerant patient (McCaffery, 1995). Further, adequate pain relief does not cause respiratory depression (McCaffery, 1995). And finally, regarding opioids, addiction and the terminally ill, McCaffery quotes the American Cancer Society and National Cancer Institute: "'Pain relief is a medical reason for taking narcotics. Therefore, if you take narcotics to relieve your pain you aren't an addict no matter how much or how often you take narcotic medicines' (McCaffery, 1995 p.61)”.

\section{Applicability of McCaffery's Practice Framework}

Technological and research fueled therapies have turned many "terminal" diseases into chronic conditions and dramatically increased length of life; and for many, quality of life as well. Even so, in late stage disease management, eventually all the sophisticated life prolonging measures are stripped away, as their usefulness passes. What actions then can be taken? What is left to "do"? How do we address the anger of a patient's loved ones who have unrealistic expectations of the healthcare system, or have no understanding that our human machinery truly reaches a point where there is no curative intervention? It is at this juncture that the real question often becomes are we saving life, or prolonging suffering?

Quality care at end of life always comes down to a series of "decision trees" of sorts, and choosing and releasing interventions in order to find the unique path or solution that affords the greatest good at the time. The practitioner must step back and support patient and family to reestablish goals and re-define quality of life and roles, ideally utilizing an interdisciplinary approach. Sometimes "healing” becomes a psychosocial or spiritual journey, creating a healing environment, or supporting an individual's self healing. Sometimes it can become aggressive physical symptom management, and sometimes it is simply providing therapeutic presence and 
witnessing the existential suffering. Being "present", being part of a patient and family journey and acting as a healing guide through the journey is basic to effective end of life care.

The complexity of pain and symptom management in end of life care coupled with a cooccurrence of substance use disorder requires innovation, development of trusting relationships, personalized intervention and mutual goal setting. The practice framework supplied by McCaffery's teachings on pain assessment and management provide a structure and lens through which to view pain in the terminally ill patient with a co-occurrence of substance use disorder.

\section{Description of the Relevant Literature}

A turning point in the scientific interest in the study of pain began with the proposal of the gate control theory of pain in 1965 (Robert, et al., 2010). Using that date as a starting point, when one searches the term "pain management" in the CINAHL database there is one lone article identified in the year 1965. By 2014 this number had risen to 906 articles published for the year. Interestingly, using the year 1965 again as a datapoint, when one searches the individual terms "substance abuse" and "drug abuse" as well as "hospice" and "terminal illness", no publications are found. By the year 2014, however, 2007 articles on "substance abuse" and 699 articles on "hospice" can be found. It has been clear from this author's search of the literature in CINAHL and multiple other databases that there has been a paucity of knowledge on these phenomena and that these fields are underdeveloped separately and even more-so as cooccuring phenomena.

A bibliometric study on the evolution of the scientific literature on pain between 1976 and 2007 by Robert, et al. (2010) showed 6 fold growth in the number of articles on pain with 
the number of journals specifically dedicated to pain growing from 2 in 1976 to approximately 40 in 2007 . Additionally, there has been tremendous increase in the number of countries participating in pain research, with the EU surpassing the US in terms of productivity. Despite this impressive growth, the science is young and dissemination of the literature to practice has a considerable way to go. There remains an underemphasis in the education of health professionals (in particular the prelicensure education) which represents a major barrier to effective pain management in all populations (Fishman, et al., 2013). From the work of the Summit for Interprofessional Consensus on Pain Management Competencies, Fishman, et al. (2013) have defined a set of consensus driven core competencies encompassing four domains - including the nature of pain, assessment and measurement, pain management and the context of pain management, along with values and guiding principles within each domain. The universal nature of these competencies are to be applied across settings, populations and models of care and address the needs of children, adults, acute and chronic pain and pain at end of life. However, there is considerable challenge now to incorporate this work into educational curricula and then into practice.

Anderson (1982) utilizing nursing process as an organizational framework looked at an international review of the literature on the cancer patient in pain. This vintage paper from 1982 was one of the first of its kind to systematically review the pain management literature. Anderson identified that there were relatively few studies on the subject of pain and that there was a great need for more research in order to "help cancer nurses recognize their unique role in pain assessment and management for cancer patients"(p.33). Since that time, the study of pain management has expanded, but there is much work to be done. A systematic review by Minozzi, et al. (2012) concluded that use of opioid analgesics for chronic pain are not associated with an 
increased risk for addiction. However, the authors cite as their most impressive finding the deficiency of good quality studies on the subject of pain and opioid analgesics, given the widespread concern by many regarding the use of opioids for managing pain.

While there are many descriptive articles, nursing is under-represented in the pain management research literature. In a review of select studies and literature between 1979 and 2007, Morgan \& White (2009) summarized results about nursing knowledge on the topic of "pain and addictive disorder". They found that much of the literature of the late 1990s and early 2000s on co-occurring pain and addictive disorders primarily concerned the HIV/AIDS population and those in methadone maintenance programs. Their findings document an historical lack of education on the subject of pain management and addictive disorders in general as well as an atmosphere of "opiophobia". They further found nurses to be more "punitive, negative and authoritarian"(p. 46) towards patients with addictive disorders, but that although they demonstrated marginalizing and stigmatizing behaviors, nurses felt guilt and shame over their own responses and judgmental behaviors.

In a study by Wilson (2009), which in part replicated the classic 1992 "Ben \& Mike" simulation study by McCaffery and Ferrell, where two groups of nurses were presented with two clinical scenarios where the socio-economic status of the two patients was manipulated, while all other characteristics and data remained constant. "Mike" was a businessman and "Ben" was a construction worker and unemployed. Their simulated clinical histories were exactly the same, with both having sustained injuries in a traffic accident and were in pain, the only difference between the two was their socioeconomic status. The intent of the assessment of these two hypothetical patients was to demonstrate how patient characteristics might influence pain management decisions.. The vignettes were similar in the Wilson (2009) study, however, the 
two groups of nurses were generalist and hospice nurses. The participants were required to fill out a questionnaire addressing pain knowledge, pain inferences, general attitudes and beliefs about pain management as well as to identify the patients' pain level and make decisions about pain management. The generalist nurses undermedicated but were very concerned about respiratory depression, tolerance, and addiction. The hospice nurses were found to be less biased about lifestyle, but also undermedicated the patients in the scenarios. The conclusion was that current educational and clinical experiences of all nurses was insufficient to erase bias and myth.

On a more positive note, in a survey of 145 VA nursing staff, Goebel et al. (2010) reported that nurses with more experience, higher education levels, and with documented higher levels of self efficacy and self confidence were more likely to discuss addiction fears with patients concerned about the effects of pain medication than less experienced staff. Goebel et al. (2010) further recommended that efforts to improve pain management should also include focus on the retention of experienced nursing staff.

Health care professionals may "know" but may not "do". A case in point is in the use of common pain assessment/screening tools. A $2010 \mathrm{VA}$ funded cross sectional visit based cohort study with survey by Shugarman, et al. (2010), evaluated factors impacting 94 nurses and other staff use of pain assessment tools with 465 patients during routine visits. They found that underestimation of pain occurred in $25 \%$ of encounters, and overestimation in $7 \%$. In half the encounters, staff did not follow pain assessment protocols or use mandated tools. Again, rather than believing that nurses were noncompliant, unmotivated employees, one could conclude that there are inadequacies in the standard pain assessment tools, or that there might be other system failures. 
Barriers to adequate pain management span 40 years of literature. A 2006 survey by Fineberg, et al. identifies that despite hospital guidelines supporting unrestricted opiate administration to treat end of life pain, as well as clinician support of the concept, pain was often undertreated. Common causes for undertreatment were system barriers, knowledge deficits about pain management and institutional policy, and personal bias. In a cross sectional multicenter study of 525 patients with cancer diagnosis by Anton, et al. (2012), the topic of inadequate pain management despite availability of effective analgesics was addressed. Patient attitudes and beliefs around pain and use of analgesics impacted their pain management, and patient perception of pain was highly influenced by communication with as well as information provided by the health professional. Those who were dissatisfied with their pain relief stated they were not asked as frequently about their pain and felt that their physicians were less involved.

In a quantitative descriptive cross-sectional survey study looking at barriers to cancer pain management in oncology nurses in Jordan (Al Khalaileh \& Al Qadire, 2012), concerns of nurses were abundant despite clinical knowledge and education. There was a view that management of cancer pain was futile, devaluing patient reports of pain. and generally, that pain medication is more harmful than beneficial. In a survey of patients with advanced cancer by Miccinesi, et al. (2012) looking at end of life preferences, pain and dyspnea were the two symptoms most often reported as intolerable, and the majority of patients stated that use of opioids was acceptable although some routes of administration were less desirable. Biases around addiction and attitudes were linked to the amount of dialog with physicians.

A systematic review by Lorenz, et al. (2008) provides review of the evidence of interventions to improve palliative and end of life care. This study also looked at the literature from 2005-2007 and includes articles addressing end of life and interventions to address pain, 
dyspnea, depression, advance care planning, continuity of care, and caregiving. The diagnoses focused on in this study were cancer, chronic heart failure, and dementia. The authors evaluated the strength of the evidence and rated study design utilizing the GRADE system, scoring the evidence as high, moderate, low, or very low. After identifying 24,423 titles, ultimately 33 high quality systematic reviews and 89 intervention studies were included. This robust study reported numerous research gaps/weak evidence for managing non cancer pain, dyspnea, depression, and insufficient evidence for addressing dyspnea in cancer and heart failures. They identified a need for further research in spiritual/bereavement domains as well as technical interventions such as palliative surgery, etc. They identified strong evidence for treating cancer pain with nonsteroidals, opioids, radio nucleotides and radiotherapy. They identified strong evidence for treating dyspnea with beta agonists and opioids in COPD and strong evidence for psychotherapy and antidepressants when there is a cancer diagnosis.

A review of complementary and alternative literature by Running and Turnbeaugh (2010) provided exploration of the evidence on the effectiveness of complementary therapies (CT) and cancer pain and symptom control. They searched the literature for studies of prevalent types of pain described by patients with cancer - bone, chronic, neuropathic, and visceral. They classified the studies by level of evidence. Of all the modalities, they noted that massage therapy and energy therapies have shown some effectiveness in cancer pain management but there needs to be further trials with larger number of participants in order to evaluate efficacy. They cautioned that CTs should not be relied upon for total pain control and that use of integrative approach with both CT and pharmacological therapy may be more beneficial than pharmacological treatment alone. 
Consensus in terminology has been a stumbling block in the study of "substance use disorder" (SUD, the DSM-V amalgamated term for the DSM-IV terms "substance abuse" and “dependency") as well as the pain management literature. Knudsen, et al. (2009) provided a systematic literature review to identify the classification systems used to classify cancer patients with pain. They looked at 692 papers covering a 20 year span. Of these, 92 papers were included for further analysis - 55 clinical studies and 37 educational papers. They found that there was no international consensus on the 6 classification systems identified. And of these, three classification systems were classified as partially validated and they noted that none were consistently or widely applied. They pointed out a need to develop an international consensus on how to classify pain in patients with cancer. They projected that development of a "cross culturally robust international system that is evaluative, descriptive and prognostic" (p.305) will lead to better control of cancer pain.

Examining the terminology of pain, physical dependence, pseudo addiction, and addiction, Bell and Salmon (2009) critically evaluated "discourses on pain management and addiction" written by and for physicians. They found in the literature a desire to overcome opiophobia by separating the consequences of "proper" use of opioids for "legitimate" patients as opposed to feeding addiction, and an attitude of the "deserving pain patient" vs. the "undeserving addict". They pointed out that a dichotomy exists - that while pain is assessed via subjective reports, clinicians are often warned not to trust a patient's self report. Further, physicians are essentially being asked to be the moral and legal gatekeepers. They also remarked on the challenge for physicians in deciding whether or not to prescribe opiates for pain in the setting of potential pseudo addiction. Further, they suggest that pseudo addiction is perhaps simply a sanitized syndrome of pain patients who are white, middle class, and do not have (or do 
not appear to have) a history of substance abuse. They further outlined that because of the economic costs of pain, proper pain relief is tied to a patient's economic worth as productive member of society. They summarized that the discourse in the literature on the subject of pain and addiction only serves to further stigmatize "the addict" and undermined access to adequate pain management.

Prevalence of opioid use for chronic non cancer pain management (CNCP) has increased, leading to controversy and challenges. Edlund, et al.(2010) noted that opioid use for chronic non cancer pain was on the increase in their analysis of prescribing trends between 2000-2005 in commercially insured patients covered by Medicaid. They further pointed out the impact of cooccurring mental health diagnoses and/or substance use disorder. For the commercially insured, chronic opioid use increased by $34.9 \%$ in individuals with mental health diagnoses and/or substance use disorder, as opposed to $27.8 \%$ in the population without these disorders. They further noted that in those insured by the Medicaid system, chronic opioid use increased by $55.4 \%$ for those with a mental health or SUD and by $39.8 \%$ in those without diagnosis of these disorders.

While some believe this is a sign of improved pain management, others see this as a concerning trend. In a mixed methods exploratory study looking at the acute pain management of those with SUD in the acute hospital setting Blay, et al. (2012) concluded that because of altered responses to analgesia, differences in cultural values, and health professionals perceptions, the SUD population is truly different, and that they require "significant deviation" from pain management protocols. In a review of recent literature on acute and chronic pain in patients on methadone maintenance and addiction treatment, Eyler (2013) concludes that pain responses in patients on methadone maintenance are different from those patients who are not, and the pain 
medications for these patients may also differ significantly. She identified that opioid induced sensitivity to pain is long lasting in this population, and the presence or absence of chronic pain may impact their perception of acute pain. Interestingly, gabapentin has been used successfully to reduce this sensitivity in some patients. Eyler (2013) further emphasized studies demonstrating the "underlying tension" between prescribers and patients around the subject of pain management with underlying opioid addiction. She concluded with recommendation of the need for rigorous studies to inform health care providers regarding effective pain management approaches for this population.

Wachholtz, et al. (2015) examined key empirical and theoretical papers on the relationship between hyperalgesia,tolerance, and the use of opioids. They acknowledged that research on differences in the psychophysiology of patients with pain and opioid misuse disorders is in the early stages - but suggest that alterations in psychophysiological pathways may be present in patients with SUD. These alterations may result in greater levels of hyperalgesia, and hyperalgesia may develop as early as a month after beginning use of short acting opioids. They noted too that some have hypothesized that addiction and hyperalgesia may come from the same area of the brain. They called for continued research to develop novel, integrated treatments for these complex patients.

In a large, older study, based on data from the Danish Health and Morbidity Survey, Eriksen, et al. .(2006) concluded that while opioids improved CNCP, function and Quality of Life (QOL) for some, there was no consensus. They also stressed that the increase in opioid use was not only the result of clinical need and recommendations from pain experts, but also the result of sales promotion activities by pharmaceutical companies. 
Use of opioids with abuse deterrent formulations, such as the addition of naltraxone, is promoted by some. Pade et al. (2012) call the abuse of opiates a "public health crisis" and call for new approaches to treat patients with CNCP who also have SUD. They report on the development of a "co-occurring disorders clinic" to treat patients simultaneously for chronic pain and addiction in a VA clinic system in New Mexico. Co-occurring opioid dependence and chronic non cancer pain (CNCP) were treated with bupenorphine/naloxone . In their retrospective chart review, including state prescription monitoring and random urine drug screens, their results demonstrated modest success with patient compliance, pain relief, and relapse.

Similarly, Ling, et al.(2011) citing case studies, recommended that physicians find a balance between limiting potential adverse effects of opioids while maintaining their "legitimate access" for treatment of pain. They further called for research directed at abuse deterrent formulations and research on genetic risk factors for opioid dependence and hyperalgesia. Michna (2014) in a metaanalysis sponsored by Pfizer searched PubMed and Cochrane Library databases to compare the safety and efficacy of opioids with and without abuse deterrent formulations. The findings demonstrated comparable efficacy profiles.

Concern is expressed by some regarding the misuse of opioids in patients with cancer diagnoses. Starr, et al. (2010) in a descriptive article stated that even in patients with a terminal cancer diagnosis, $50-60 \%$ survive at least two years which can lead to problems for those with history of addiction. They call for consensus between clinicians regarding opiate prescribing practices, addiction screening, and use of effective pain assessment and documentation tools. Similarly, Koyyalagunta, et al. (2013) in a retrospective analysis of patient records, noted that with improved cancer survival and prolongation of life there is greater opportunity for opiate 
misuse. They reported that their findings are similar to the findings of other studies looking at risk factors for opioid misuse in patients with chronic pain - that is, those who are younger, have co-occurring anxiety and depression are at higher risk. They also noted that the literature on the care of the cancer patient with a history of SUD is scant. They recommended adopting a risk stratification system that would trigger further assessment of patients found to be at higher risk.

Noting ongoing debates about addiction and use of strong opioids in relief of cancer pain, Smith et al. (2007) in a small literature review researching "the controversial issues" contributing to poor pain control, found that patients without previous chemical dependency are rarely “addicted" to pain relievers. These researchers recommended that education be current and ongoing - especially for the generalist staff. Further, they recommended that there needs to be improved and excellent assessment skills, and finally that use of the World Health Organization (WHO) analgesic ladder may not be appropriate for this patient population. Gaertner and Schiessl (2013) emphasized that patients suffer because available options for cancer pain treatments are underutilized. They looked at guidelines, meta-analyses, systematic reviews, treatment recommendations and articles from 2012 for review of findings, treatment recommendations and controversies in cancer pain management - including new agents, efficacy of older/established agents and conflicting recommendations from guidelines. Their primary conclusions were that new pharmacologicals hold promise for treatment, but the gold standard must be establishment of early palliative care as an integrative, multi-professional, interdisciplinary collaboration.

Blackhall, et al. (2012) expressed concern that the problem of potential SUD and diversion in hospice must be addressed at the policy level. They reported a lack of information in the literature documenting how hospices should address SUD in hospice patients and their 
families. Their survey of Virginia hospices demonstrated that less than half of the hospices surveyed had mandatory substance abuse training and policies. Only 38\% of those surveyed felt that SUD and diversion were problems for their agencies - which seems to be an optimistic view. The authors called for research into the topic and for guidelines to address management of SUD and pain at end of life

For $40+$ years there are recurrent recommendations for research and education on the topic of opiate pharmacology and prescribing, pain and addiction. However, very little has been written on these topics in setting of life limiting illness. Goldstein and Fischberg (2008) provided a review of 17,000 citations distilled down to a handful of quality studies regarding pain management, non pain symptom management, nursing home care, prognosis, and quality of care within palliative care. Conclusions of key individual studies were documented and reiterated some "bottom line" clinical suggestions - among them: stop withholding opioids at end of life - as there is no evidence that opioids hasten death or cause other harm.

In this literature review, representative quantitative and mixed method studies including systematic reviews, underscore the clinical challenges and issues in pain management, SUD and life limiting illness. The existing quantitative and mixed method literature is not able to adequately address the central topic of this project and provides no consensus as to how to manage pain and provide comprehensive and compassionate care of this population at end of life. In this project, metasynthesis of the recent qualitative literature will provide additional compelling evidence upon which to base recommendations for practice and further research.

\section{Methods}




\section{Project Design.}

High quality systematic reviews are the gold standard for summary of evidence in the literature. They can minimize bias and improve reliability of conclusions on which clinical practice guidelines can be based (Riesenberg \& Justice, 2014). The systematic review makes clear what is known and not known on a given subject and the systematic review is relied upon heavily to inform clinical decision-making (IOM, 2011 as stated by Riesenberg \& Justice, 2014). Methods for developing the evidence base in end of life care must be rigorous and must reflect the complexities of caring for this population. Some research with biological/quantitative outcomes may be of value - for instance tumor response in patients receiving palliative care. However, a more effective measure of interventions in palliative care may be whether an individual or family perceive improvement in quality of life, feel better overall, feel supported or otherwise perceive a good outcome (Fleming, et al, 2008). Thus, qualitative inquiry can be especially useful in addressing the constructs of living with and managing the effects of disease, the personal and cultural meaning of disease, end of life decision making, as well as the political, historical, cultural context impacting access to care, health promotion, disease prevention, and health disparity (Sandelowski \& Barroso, 2007). The synthesis of qualitative research aims to review and integrate the findings of qualitative studies to inform practice and may include thematic descriptions or interpretive explanations of the research. I decided with my project chair that the best strategy to inform practice on the topic of pain, SUD and EOL, given the dearth of literature, was to undertake a qualitative metasynthesis.

A qualitative metasynthesis is defined by Sandelowski and Barroso (2007) as: “...an interpretive integration of qualitative findings in primary research reports that are in the form of interpretive syntheses of data: either conceptual/thematic descriptions or interpretive 
explanations"(p.199). For guidance on the mechanics of a qualitative metasynthesis of nursing research, we utilized Sandelowski \& Barroso's Handbookfor Synthesizing Qualitative Research (2007). This reference provided direction on utilizing qualitative methods to analyze and interpret the data and then integrate and synthesize the findings.

\section{Investigative Techniques}

A five phase approach was utilized to collect, analyze, interpret, and synthesize the qualitative literature on the phenomenon. In a metasynthesis, the findings are derived from taking all the studies and viewing them as a whole. It is not a summary of unlinked data, but instead an integrated interpretation and explanation of the data around a phenomenon (Sandelowski \& Barroso, 2007).

Phase I comprehensive retrieval of the literature. Temporal, topical and methodological parameters were defined for the literature search process. Beginning 9/1/14 and ending 2/15/15 multiple electronic data bases were used to search multiple terms. Initial searches confirmed prior searches of the literature, revealing that there is very little written on the specific topic of "pain and end of life when there is a co-occurrence of substance use disorder", and minimal qualitative studies. It was determined that the best strategy to inform us on the project topic was to look at similar phenomena using different combinations of search terms. So the literature search was broadened to look at the topic elements in any combination (e.g. pain+SUD, pain + EOL, SUD +EOL).

As the process unfolded, search terms were modified to yield more titles. Footnotes and references of relevant studies and articles were reviewed for potential retrieval of yet more studies. Names of individual authors were searched in an attempt to retrieve more published work on the phenomena. Citations and abstracts were appraised for relevance, and if the study 
found was qualitative or mixed method and informed on at least two of the combined topics of pain, substance use disorder, and end of life, they were initially selected. This process was fairly exhaustive and the combined citations reviewed exceeded 1000 titles. If the title was found to be relevant to the phenomenon, the abstract was read. If the abstract proved significant, the full study was reviewed. At that point, a study was included, excluded, or set aside for further review. While the searching was extensive, the actual number of relevant qualitative studies identified was relatively small.

Phase II selection of studies, initial analysis. Finally, 38 studies were included in this project. A weighted "quality appraisal" per se was not undertaken in the selection of studies. Synthesists argue against having a "checklist mentality" when evaluating the "quality" and usefulness of qualitative research, and that the "quality" of a study should be treated as simply one of the characteristics (Sandelowski \& Barroso, 2007). The studies included were those studies from 2010-2015 written in English, found in peer reviewed journals, and were either qualitative or mixed method with heavy qualitative content where the qualitative findings could be separated from the quantitative. We did accept several systematic reviews which captured earlier literature on the topics. Sandelowski and Barroso (2007) point out that the "the major device enabling comparative appraisals is a data display showing the same key elements of information in each report together" (p.79). For this project, the theoretical/conceptual framework, research question/hypotheses, methodology, results, conclusions/themes/key points and significant quotes from each study were manually summarized in a matrix to facilitate appraisal.

Initial analysis and comparison of the studies identified that they yielded data from the distinct individual perspectives of the patient, nurse, physician/prescriber, family/caregiver and 
society. After further examination, we found that the studies could secondarily be catorized by at least 2 of the three phenomena of interest: EOL and Alcohol/Illicit Drug Use; EOL and Pain; Chronic Non-Cancer Pain; Opiate Dependency and Pain; and Cancer Pain Management. The studies were re-ordered, grouping by these pain/substance use disorder/EOL themes and then analyzed again from the "voice" of each perspective (patient, nurse, physician/prescriber, family/caregiver - the one study from societal perspective fell within the theme of "Cancer Pain Management" only).

Phase III interpretation of the literature. The search for recurrent themes in data and the integration of themes into a unifying concept is foundational to qualitative inquiry (Sandelowski \& Leeman, 2012). In a metasynthesis, the researcher is able to integrate the findings of studies and describe or explain the phenomenon and "craft one or more metasynthesis...their validity does not reside in a replication logic but rather in an interpretive logic, whereby findings are reframed...(Sandelowski \& Barroso, 2007 p. 152)”. In this project, we were looking at the literature for an integrated whole from which we could inform the practitioners who work with this population. Between 9/1/14 and 3/22/15, my Project Chair and I met at regularly scheduled intervals in person and electronically for research and interpretive sessions. Separately and then together, we examined emerging themes from the selected studies and the relationships between themes. A "taxonomic analysis" was undertaken as a strategy to further capture and penetrate the findings of the selected studies. Findings were extracted from each pain/SUD/EOL theme category (EOL and Alcohol/Illicit Drug Use; EOL and Pain; Chronic Non-Cancer Pain; Opiate Dependency and Pain; and Cancer Pain Management) and from each perspective (patient, nurse, physician/prescriber, family/caregiver and society). The resulting document "Taxonomy of Findings" provided a platform to further examine themes. This process 
was inductive and interpretive. Thematic analysis and interpretation continued until saturation and integration was reached.

Phase IV synthesis of key findings. Ultimately, the interpretive synthesis of the data yielded four key findings: the overarching theme of "knowing the patient", along with "fear", "system barriers", and "mutually exclusive rituals between health professional and individual with SUD”.

Phase V recommendations for practice, and recommendations for future research. Sandelowski \&and Leeman (2012) recommend that in order for the findings in qualitative health research to be more significant and actionable, the findings must be presented in the language of intervention and implementation. The final phase summarizes how the findings of this project inform practice when caring for a patient at EOL with SUD, as well as making other practice recommendations and recommendations for further research.

\section{Rigor}

Sandelowski and Barroso (2007) emphasize a focus on descriptive, interpretive, theoretical and pragmatic validity in order to assure valid procedures and outcomes. Descriptive validity was maintained by ensuring an extensive and exhaustive search of the literature and by accurately appraising the information in the studies utilized. Interpretive validity was maintained by accurately representing the points of view of the researchers in the studies utilized. Theoretical and pragmatic validity of the methods utilized in this project were assured by holding regularly scheduled research meetings and interpretive sessions, by having both the DNP student and Project Chair (who has expertise in qualitative research methods) appraise the identified literature and by ensuring an "audit trail" of the processes and the studies was utilized.

\section{Human Subjects}


No human subjects were involved in this project, and this qualitative metasynthesis is identified as "exempt" per Section 3.5.2.C of the Policy \& Procedures for Research with Human Subjects at California State University, Fresno. Evidence utilized has been wholly from the existing published literature in the areas of interest in this study.

\section{Discussion of Key Findings}

\section{Key Finding \#1, Knowing the Patient}

The importance of "knowing the patient" in the setting of pain, end of life, and substance use disorder is the overarching finding of this qualitative metasynthesis. What it means to "know the patient" requires cultural competency, understanding of their worldview, awareness of their “currency", strengths, challenges, what they see as elements of a good quality of life as well as barriers to obtain that quality of life (St. Marie, 2013). Understanding the meaning of and barriers to good quality of life (QOL) is particularly important in order to gain knowledge of the individual living with pain, with or without life limiting illness, and with or without SUD. Elements of good quality of life include pain relief, to feel "normal", to be able to function, live life unafraid and meaningfully, with meaningful relationships, and to have hope for the future (DeMaeyer, et al., 2011). Additionally, the individual living with pain wants to be understood, to be listened to empathetically, respected and to not be judged for their actions around pain relief (McCreaddie, et al., 2010). They want to be heard when they share information and believed when they say they are in pain (Esquibel \& Borkan, 2014). Individuals with history of SUD do not want to be spoken of in stigmatizing terms such as "addict", "drug seeking", “junkie" (St. Marie, 2013). 
Barriers to good quality of life for individuals with substance use disorder can include unor undertreated physical and existential pain, the loss of health, and fear of an impending and early death (Dzul-Church, et al., 2010). Drug craving and fears around withdrawal often lead to deceptive behaviors, which in turn undermine relationships; yet loss of key relationships and the resulting isolation are consistently, identified as significant barriers (Roe, et al., 2010). A chaotic lifestyle that includes illegal activities may increase stress and anxiety (McCreaddie, et al., 2010). Co-occurring mental illness further disenfranchises individuals, impacts QOL, and is seen as a barrier to effective pain management as a result of the difficulties in distinguishing what contribution each condition has to the patient presentation (Barry, et al., 2010). There may also be limited access to health and social services (Dzul-Church, et al., 2010), which impacts QOL.

In a 1993 study, Tanner \& Benner described "knowing the patient" in terms of expert nursing practice - knowledge that moves beyond empirical data about the patient to an in depth understanding of the patients patterns of responses, and knowing "the person". The findings of this qualitative metasynthesis are in harmony with this concept. Health care providers must be aware of their own biases and blind spots as well as the potential for conflicting priorities. In developing the therapeutic relationship, the health care provider must set the tone for openness, transparency, honesty, and connecting with patients with SUD "as people not problems" (McCreaddie, et al., 2010, p.2738). They must effectively communicate, anticipate needs and problems, and take the time to be truly present in patient interactions (Browall, et al, 2014). There must be goal setting and mutual expectations outlined. Strengths and inner resilience must be validated and supported (Roe, et al., 2010; Dzul-Church, et al., 2010). Pain must be addressed within the patient's subjective cultural and social constructs (Hazous \& Knobf, 2014; Luckett, et al., 2013). Further, the health care provider must be educated in pain management, 
end of life care and how the disease of SUD impacts the interactions (Simone, et al, 2012). Being open to harm reduction strategies and improved educational preparation of the generalist health professional on pain, end of life care and SUD is key (McNeil \& Guirguis-Younger, 2011).

Individuals have a need to give meaning to their actions, especially hidden behaviors such as substance abuse (Rigg \& Murphy, 2013) and underserved individuals with substance use disorder at end of life may require greater understanding by health providers of the impact of their life stories on their current reality (Dzul-Church, et al., 2010). However, whether or not there is a history of SUD, pain exists within the individual's cultural and social context and the subjectivity of their pain experience is undeniable (Luckett, et al., 2013). Pain may impact every aspect of an individual's life and may lead to feelings of anger, frustration, sadness, despair, powerlessness, helplessness and loss of control. And significantly, for the individual with life limiting illness, pain may signal a worsening of the underlying disease process (Luckett, et al., 2013). The individual is the ultimate expert about their own pain, and what pain means to them must be appreciated (Knudsen, et al., 2012).

\section{Key Finding \#2 Fear}

"How very little can be done under the spirit of fear... (Florence Nightingale as stated in Cipriano, 2015)". However, fear of personal or professional negative consequences or punishment can be a powerful motivator of behavior. In the findings of this project, each perspective - Patient, Provider/Prescriber, Nurse and Family/Caregiver displayed a unique combination of fears, although there were fears that these groups had in common. 
Each group was identified as being fearful of addiction (Luckett, et al., 2013). The patients with SUD were fearful of craving and of withdrawal (St. Marie, 2013). Patients had a fear of the unknowns in their future, fear of their personal "core" being exposed and vulnerable (Dzul-Church, et al., 2010). They were fearful of pain and of death (St. Marie, 2013) and of the side effects of pain medications (Coker, et al., 2010). Patients and caregivers both were fearful of pain, and were both also fearful of disease progression (Flemming, 2010). Both nurses and caregivers were fearful of overmedicating (Coker, et al., 2010), and fearful of not being able to provide relief (Flemming, 2010). Caregivers were fearful of undermedicating as well (Luckett, 2013). Nurses and Provider/Prescribers were fearful of being judged by their peers, and both groups were fearful of litigation (Zerzan, et al., 2011). Provider/Prescribers felt the weight of potential consequences around prescribing opiates by DEA and licensure (Zerzan, et al., 2010), and were also fearful of prescribing opiates due to lack of familiarity (Gardiner, et al., 2012).

\section{Key Finding \#3, Mutually Exclusive Behaviors}

The patient with SUD and pain; and SUD, pain, and a life limiting illness most often present in the primary care or emergency department - not into a setting with a high degree of expertise managing any of these three conditions. There may be a mismatch in perceptions and expectations of the therapeutic relationship (Luckett, et al., 2013). Clinician rituals and routines tend to be organized and efficient, authoritative, and in control (McCreaddie, et al., 2010). The clinician may perceive those with SUD as immoral, responsible for their health outcomes (DeMaeyer, et al., 2011). In contrast, the patient who has a SUD may mistrust the healthcare delivery system - and then act in a way that demonstrates this mistrust - e.g. medical noncompliance, aggression, and self discharge (McCreaddie, et al., 2010). For the clinician, the priorities of care may be treatment of the underlying disease, safety, prevention, and compliance 
with regulatory bodies and employment systems . Provider/Prescribers and nurses who are unfamiliar with the management of pain in a patient with SUD may be caught off guard by the conflicting priorities and potential for deception, chaotic, and potentially illegal activities (such as diversion, illicit drug use, criminal activity to obtain illicit drugs, etc.) which contrast with the rules, regulations and timeliness pressures of the "mainstream" health care delivery system (McCreaddie, et al., 2010). However, the behaviors used to obtain medications allow the individual with SUD to prevent withdrawal - which may be their priority (McCreaddie, et al., 2010). The individual with SUD may conceal information (St. Marie, 2014), while the clinician needs transparency in order to plan effective care. There may be what is perceived as mismatch between patient subjective description of pain, clinician observation and "objective measures" (Barry, et al., 2010). Reports of pain may be taken as more credible by clinicians when life limiting illness is present. At the same time, some individuals with SUD have been known to intentionally injure themselves (purposely contaminating wounds, causing musculoskeletal injury, etc.) and others have been known to use conditions found on underlying radiological imaging to "prove" they have pain (St. Marie, 2014).

For the individual with SUD, there is often isolation from the larger society, personal relationships, health care facilities, and other resources, and their needs can be complex and extensive (Dzul-Church, et al., 2010). Lives of those with history of SUD may be marked with loss of relationships, homelessness, imprisonment, assault, and heavy regret, loneliness and selfreproach (Dzul-Church, et al., 2010). The relationship with a clinician in the setting of limited social support can be a true source of comfort (Dzul-Church, et al., 2010), and the relationship between the clinician and the individual with SUD in end of life care may represent a "last chance" to be "known" and develop a meaningful human relationship. This is a dynamic often 
experienced in end of life care in the setting of a patient's estrangement and isolation. However, addressing these needs can contrast with time constraints and payer driven reimbursable activities for the health professional (Yanni, et al., 2010).

\section{Key Finding \#4 System Barriers}

System barriers impacting adequate pain assessment and management and to "knowing the patient" were identified. Interpersonal communication, interagency, and interdisciplinary communication were found to be barriers to effective interdisciplinary goal setting, careplanning, and care coordination across all the stakeholders (Jablonski \& Duke, 2012; Matthias, et al., 2010;Upshur, et al., 2010). This project also identified that inadequate educational preparation for generalist nurses, physicians and other providers about pain, addiction and end of life was a significant barrier to effective care (Hazous \& Knobf, 2013). There is also often inadequate institutional support for developing best practices/policy/procedure around pain and EOL care (Jablonski \& Duke, 2012).

Even when institutional support and best practices have been established, there may be inconsistent follow- up and reinforcement over time (Coker, et al, 2010). Lack of time, excessive workload for the health care worker and inadequate financial resources of the institutions are barriers (Coker, et al., 2010). Care of the population with pain, SUD and life limiting illness often requires more time and resources than the 'average" patient. Institutions and primary care providers are not compensated by reimbursement sources for this increased need (Barry et al, 2010).

The 0-10 numeric rating scale (NRS) for pain, nearly universally used by organizations, was also identified as a barrier to pain assessment and management. There was a recurring 
theme within the studies of inconsistent or inappropriate use by clinicians and by patients. It was identified that a pain tool needed to reflect more of a "common language" between clinician and patient (Luckett, et al., 2013; Hazous \& Knobf, 2013).

\section{Limitations}

Limitations of this qualitative metasynthesis, similar to other syntheses of qualitative literature are foremost that the synthesis is reliant on the reporting and potential bias of other authors. That being said, there is no consensus on criteria for judging the quality of qualitative research and many legitimately argue that quality is only one of the characteristics by which to judge the usefulness of a qualitative study. Additionally, because there is so relatively little written specifically on the phenomenon of this project, it is not clear that the literature utilized does indeed fully address the phenomenon. Finally, this project is limited by the possibility that despite efforts to include all relevant studies, a key informative qualitative study may have been overlooked.

\section{Recommendations for Practice}

\section{Strategies for Care of the Individual with SUD and Pain at EOL}

There is evidence in the literature that practice regarding pain management has often been led by myth and bias as opposed to evidence based knowledge (Wilson, 2007). There is evidence too that best practices are not uniformly delivered (Blayney, et al, 2012). Clinical practice must be based on a combination of evidence, integration of individual clinical perspective, patient preferences, and practice generated data as well as best available evidence from research (Grinspun, et al., 2011). The literature shows time and again that pain continues to be a treatment challenge (Khalaileh \& Al Qadire, 2012), and remains one of the most common 
symptoms requiring nursing intervention - yet many are not confident in actions to be taken (Tracy \& DiNapoli, 2012). There is a need to provide the interdisciplinary team in end of life care with an overview of the state of current evidence based literature on pain management, EOL and SUD, as well as understanding of the gaps in evidence and areas for future research.

The combination of the key findings of this project, recommendations from the arena of pain management and SUD, along with expert clinical knowledge and experience of end of life interdisciplinary team members can provide a roadmap for the care of this challenging patient population. Additionally, the findings can be operationalized into educational course content for undergraduate nurses, physicians and other clinicians. Identification of SUD, risk stratification, understanding and "knowing the patient", developing a patient/family centered care plan within an interdisciplinary team, then frequently assessing/re-evaluating and making adjustment as necessary must be the approach to care. The clinician must recognize the unique needs of those with pain, life limiting illness and SUD and tailor interventions accordingly. Failure to do so is a failure to provide adequate care.

\section{Identifying the Patient with History of SUD and Assessing Risk}

The value in identifying the patient with active or history of SUD and pain at EOL is to put solutions in place early on which support provision of compassionate, safe, effective, rational pain management and EOL care. Gourlay, et al. (2005) were the first to recommend that pain medicine utilize a "universal precautions" sort of approach to evaluating patients - where there is “an appropriate minimum level of precaution" (p.107) applied to all patients. This approach for patients with SUD and pain has been adopted by the American Society for Pain Management 
Nursing (ASPMN) as well as International Nurses Society on Addictions (INTSA) (2012), among others.

Respectful risk assessment and risk stratification regarding potential past or present SUD is something that should be part of assessment for all patients, including patients at end of life (Gourlay \& Heit 2009). The 10 principles of universal precautions as outlined by Gourlay, et al. (2005) and Gourlay and Heit (2009) includes diagnosis and differential; psychological assessment and SUD risk; informed consent; treatment agreement; pain assessment and functional level; trial of opioid therapy \pm adjuvant followed by reassessment of pain and level of function; regular assessment of the "four 'A's" - Analgesia, Activity, Adverse Reactions, and Aberrant behavior; and finally, documentation. Risk stratification is recommended as well triaging chronic pain patients into a low, medium or high risk category (Gourlay, et al. 2005; Gourlay \& Heit, 2009). Uncontrolled substance use does not promote improved quality of life, even in the setting of terminal cancer (Barclay, Owens \& Blackhall, 2014). Barclay, et al. (2014) recommend risk stratification of both the patient and family utilizing a validated instrument such as the "Opioid Risk Tool", pointing out that the patient with uncontrolled substance use disorder and cancer have two life threatening illnesses (SUD and cancer) - and that this brings increased suffering to both the patient and family. Additionally, the regulatory climate of pain management must be considered, and Barclay, et al. (2014) wisely point out that clinicians must be the ones to inform regulatory agencies about best practices for this population, rather than have practices imposed. It is the recommendation of this author that these structures be adapted for use in the hospice setting.

\section{Harm Reduction}


"Harm reduction" is a patient centered strategy in the care/treatment of those with SUD and can be defined as a "public health approach to dealing with drug related issues that places first priority on reducing the negative consequences of drug use rather than on eliminating drug use or ensuring abstinence" (Riley et al.1999, as stated in Lee \& Zerai, 2010, p.2412). "Success" can be said to include demarginalization, development of a mutually trusting rela tionship, engagement, improved quality of life and social functioning, changes in substance use, formulation of goals and plans, and any perceived positive change (Lee \& Zerai, 2010). Most of these elements of harm reduction overlap the elements of "knowing the patient" as found in this project and are in harmony with one another.

Additionally, two of the qualitative studies utilized in this project by McNeil and Guirguis-Younger (2012), as well as McNeil, et al. (2014), demonstrated specifically the effectiveness in the integration of harm reduction strategies to improve access to and engagement with palliative and other support care services for patients living with HIV and SUD. So, extrapolating those findings, it is clear that it would be efficacious for the clinician/prescriber and interdisciplinary team to utilize harm reduction strategies to frame the end of life care and pain management interventions of a patient with SUD. In the hospice setting, we meet individuals "where they are" - and mindfulness about harm reduction strategies would be a "fit".

\section{Dissemination and Implementation}

Evaluating and understanding barriers to change implementation in the clinical setting is essential in order to achieve optimal patient outcomes (Gifford, et al, 2013). Access to research results is a known barrier to evidence based practice in nursing and medicine (Kehl \& McCarty, 2011). While evidence based clinical practice guidelines are the gold standard for care, some 
estimates indicate as many as $30-45 \%$ of patients do not receive this level of care and $20-25 \%$ of interventions may even be unnecessary or harmful (Gifford, et al, 2013). Gifford, et al.'s 2013 study categorized a number of generalizeable barriers to change implementation and recommend that leadership develop intervention strategies linked to the different barrier levels:

- $\quad$ Individual barriers - relating to a provider's knowledge, skills, attitudes and beliefs.

- $\quad$ Team level barriers - relating to interactions between the team members communication problems, unclear expectations and unclear social norms

- Organizational level barriers - relating to the practice environment - structures, equipment, policies and procedures

- $\quad$ System level barriers - relating to policy makers, workloads, staffing,

- Patient level barriers - relating to patient resistance to change, or communication challenges with other health care services/community partners.

Eventhough there may be interest in, and resonance with the subject matter of this project by clinicians, there may be challenges with implementing any practice change on individual, systems, organizational, and patient level. Many organizations are under considerable duress just to provide adequate day to day operations, often running very lean in terms of staffing. Additionally, education on subjects relating to regulatory issues and compliance, usually take precedence over items of interest for clinical practice. Provision of education, mentoring, role modeling, clarifying roles and expectations, being sensitive to organization priorities, ensuring cooperation of key organizational personnel, being flexible and sensitive to time (and time as money), and clarifying communication channels are all critical to successful dissemination of information and practice change (Gifford, et al, 2013).

\section{Personal Practice Change}


You matter because you are you; you matter to the last moment of your life and we will do all we can to help you not only to die peacefully but also to live until you die (Saunders, 1976)

To summarize what I, as a DNP, am incorporating into my personal practice and will take back to my EOL practice sites and professional organizations:

- Practice/procedure change to make early identification of those with SUD part of routine provider/prescriber, nursing and psych/social assessment

- SUD Risk stratification

- Reinforcement of the subjectivity of the patient's report of pain

- Acceptance of the patient's report of pain

- Implementation of harm reduction strategies

- Interdisciplinary team care plans reflecting risk stratification and harm reduction interventions to support the patient and family in goals of care.

- Nothing can take the place of truly "knowing the patient" -time, creative staffing and other resources must be put in place to accomplish this.

Assuring that individuals have a "good death" and good quality of life up until that time is a priority of quality end of life care. As previously pointed out, pain is often under or untreated and patients with co-occurrence of SUD at end of life are a vulnerable group known to be at even higher risk for undertreatment of pain. A place to begin the findings dissemination and implementation process is to engage Quality Assurance Performance Improvement (QAPI) committees within organizations and utilize that structure to review the research findings, strategize to adopt the findings, create a format for piloting and implementing practice change, and then further disseminate results to the larger health care community.

\section{Recommendations for Continued Research}


This project underscores the need for further research on the phenomenon of pain management at end of life when there is a co-occurrence of SUD, and development of strategies to effectively provide excellent end of life care to this population. However, this project has brought other gaps to light as well. Of particular significance are the problems raised with the widely used 0-10 Numeric Rating Scale (NRS). Within the findings of a number of the studies utilized in this qualitative metasynthesis, all participants - patients, nurses, provider/prescribers and family members identify the NRS scale as incomplete and difficult to use effectively (Upshur, et al., 2010; Esquibel \& Borkan, 2014; Luckett, et al., 2013; Hazous \& Knobf, 2013; Coker, et al., 2010; Barry, et al., 2010 to name a few...). So, there is a need for further research, development and universal dissemination of improved, valid tools of pain assessment, particularly in the setting of end of life and SUD. Based on the findings of this project, pain assessment tools must take into account the meaning of pain in the context of function and quality of life (Esquibel \& Borkan, 2014). They must be culturally sensitive and individually defined, and may be more effective if "storytelling" is incorporated (Hazous \& Knobf, 2013). There must be a common language when describing pain (Simone, et al., 2012), and the pain assessment tools and communication must be meaningful (Coker, et al., 2010). While identification of patient goals and goals of pain management are seen as important, they are not often identified (Bhatia, et al., 2014).

The concept of "knowing the patient" as a basic practice model has been recognized in the literature for well over 20 years, but has had little prominence in recent years, as many current practice environments do not create a setting conducive to this. Continuity of care, frequent patient contact, and development of positive relationships are central to knowing the patient but may not be supported, especially in the acute care setting (Zolnierek, 2014). That 
being said, one can argue that "knowing the patient" is at the core of expert care and practice. Serendipitously, "knowing the patient" was identified as the overarching theme for the effective care of patients with pain and SUD at EOL in this qualitative metasynthesis. Further research on "knowing the patient", as both a clinically effective and cost effective approach to care must be undertaken.

Harm reduction strategies are recognized as important patient centered programs which improve quality of life, social functioning, adherence, access and marginalization of the SUD population (Lee \& Zerai, 2010). There must be further research on these strategies to improve EOL care and pain management in this population.

Gourlay and Heit (2009) and Barclay et al. (2014) among others advocate use of SUD risk stratification - this could be a useful strategy in planning care of patients at end of life, but current screening tools are not specifically for use in EOL care. Further research is needed to develop and implement SUD risk screening tools for use at end of life.

\section{Conclusion}

The purpose of this project was to evaluate the qualitative research literature on the subject of pain at EOL when there is a co-occurrence of SUD, interpret the evidence, and make recommendations for practice. The project was framed by Margo McCaffery's pain definition and concepts. McCaffery's definition of pain remains a simple truth, as it was when first introduced. Pain can only be a subjective experience, and there is no more reliable gauge of pain than the individual's subjective report. The findings of this metasynthesis again confirm this. However, the findings also confirm that clinicians continue to struggle with this subjectivity. The concept of whether or not a patient is in "genuine" pain is prevalent among clinicians 
(Baldacchino, Gilchrest, Fleming, \& Bannister, 2010). It is far easier for individuals to accept a patient's report of pain if there is something objective to "see": a diagnostic, a fungating tumor, a disfiguring head/neck cancer, etc. Additionally, the literature reviewed and utilized in this project repeatedly reported that despite advances in the science of pain management and the availability of interventions, pain is often undertreated in general as well as at end of life.

For the clinician, there is clear ethical direction for the optimal treatment of pain, and failure to do so constitutes malpractice, in that the ethical principles of beneficence and nonmaleficience mandate pain relief - as pain causes harm and the relief of pain is beneficial (Head, 2011). Additionally, beginning in January of 2015, as part of CMS' Hospice Quality Reporting Program (HQRP) ( the hospice quality reporting measures mandated by the 2010 Affordable Care Act), appropriate assessment and treatment of pain is one of the "official" end of life quality measures. So while this all provides seemingly clear direction for clinicians, at the same time there remains "rigid and often punitive federal control over opioid analgesics" (Rich, 2009 as stated by Head, 2011 p. 58), the drugs which are the current mainstay of end of life pain management.

As part of a comprehensive patient assessment, nurses, nurse practitioners, physicians and other clinicians are taught to take what the patient says, combine it with what we see, hear, smell, feel, and form an assessment, and from there develop a plan of care with interventions and evaluation. We are further taught to take note of discordant and conflicting data. So it is really not surprising that clinicians have difficulty looking past their own subjective (albeit "objective") experience of the patient's pain report. Additionally, the findings of this project clearly identify fear of judgment, litigation, addiction, and diversion as motivators of behavior for the clinician in terms of pain assessment, management, and prescribing practices. This, combined with 
contradictory messages all around, lead to pain being inconsistently and suboptimally assessed and managed in all populations, not the least of which being the population with a history of SUD.

However, echoing McCaffery's basic concepts, the clinician must accept the patient's report of pain - this is indisputable, but this is not meant to be the stand alone answer to the conundrum. This begins the process that clinicians may find difficult, contradictory, time consuming, and frustrating, but this is the starting point from which pain management can begin.

The findings of this project identify the population with history of SUD as a vulnerable population at risk for being undertreated for pain at end of life. The key finding of "mutually exclusive rituals" sheds light on some of the characteristics of the individual with SUD, which make pain management in this population unusually challenging, and emphasizes the knowledge deficits regarding pain management that exist for the generalist clinician, especially with regard to SUD. As sub themes of the key finding "knowing the patient", components of good qol for individuals with pain (with or without life limiting illness, and with or without SUD) were identified along with barriers to good qol for individuals with SUD and pain (with or without life limiting illness). These findings, together with the identified "fears" from the perspective of the patient, provide greater depth and texture to the picture of the patient with SUD, pain, and life limiting illness, and provide some practice guidance for the clinician.

System barriers to effective pain management were identified in this project as well. Our regulatory and licensing bodies, educational systems, insurance/payer sources, and institution policies \& procedures, must be in alignment and in communication with each other for the comprehensive identification and care management of the patient with pain and SUD at EOL. 
The clinician must believe reports of pain, but must also invest the time, appreciate patient motives, strengths and challenges, facilitate the clarification of mutual and individual goals and expectations, and incorporate an interdisciplinary approach to pain management . Clinicians must become "culturally competent" in the care of this population - there is no shortcut to the solution, and truly knowing the patient is the foundation. 


\section{Appendix A}

\section{Taxonomy of Findings}

\section{Patient Perspective}

\section{A. End of Life and Illicit Drug Users}

"I need a doctor to come see me... a nurse or whatever. I'm getting too weak to take care of mysef. It's coming...the end. I can tell... It's getting to where I'm not going to be able to do anything...help me once, twice a week. Just help me brush my hair... make me look pretty again...(Church, et al., 2010).”

1. Lives filled with loss - relationships, homelessness, addiction, imprisonment, assault (Dzul-Church et al, 2010)
a. Isolation

b. Mistrust

2. Lives filled with regret (Dzul-Church et al, 2010)
a. Emotional/Spiritual Pain

3. Relationships with health care providers as a source of support (Dzul-Church et al, 2010)

a. Another chance to develop a meaningful relationship

4. Previous experiences with death were often sudden and violent/concern for how their bodies would be treated after death (Dzul-Church et al, 2010)

a. Mistrust

b. Fear

5. A life of coping with challenges - experiences of self advocacy, reliance on religion and spirituality (Dzul-Church et al, 2010)
a. Resilience
b. Hope
c. Survival mode existence

6. Underserved patients at end of life require greater understanding of the ways that their difficult life stories influence their experiences (Dzul-Church et al, 2010)

a. Healthcare providers must see the Humanness and know the story

7. Wish for improved relationships with health care providers and greater access to chaplaincy and other services (Dzul-Church et al, 2010)

a. Potential for improved outcomes with improved healthcare system design 


\section{B. Chronic Non-Cancer Pain (CNCP)}

"...find out about the person. What did you do? Where do you see life going? You got kids?...the only way you're really gonna understand me and keep your eye on me is I want you to know me a bit - to make sure I'm not fooling you... (Upshur, et al., 2010)”

1. Ability/Inability to accurately describe pain (Upshur, et al, 2010)

a. Inadequacy of current pain scales

2. Pain takes away ability to function (Esquibel \& Borkan, 2014), Strategies to cope with pain (Upshur, et al, 2010)

a. Survival mode

3. Pain relief is a high priority (Esquibel \& Borkan, 2014)... Many patients with CNCP benefit from high doses of opioids long term...Pain is often nerve pain (Watson, 2012)

4. Pain leads to more suffering and depression (Esquibel \& Borkan, 2014)

a. Downward spiral

5. Potential for abuse and diversion exists, but must not deny access to pain relief (Watson, 2012)
a. Trust vs. Mistrust
b. Doing the greater good
c. Importance of Education
d. Harm reduction

6. POSITIVE Perception of Physician (Prescriber) as advocate/friend - beneficial relationship when pain is validated, patient centered, shared decision making (Esquibel \& Borkan, 2014) Importance of shared decision-making, empathy, trust, understanding of pain level, clear communication; importance of a "compassionate partnership", evidence based guidelines, use of technology, direct phone or email contact and format for quality improvement (Upshur, et al, 2010)...Trust is essential

a. Importance of truly knowing the patient

b. Importance of accessibility

c. Importance of "partnership"

d. Importance of "patient centered medical home"

7. NEGATIVE Perception of Physician (Prescriber) as "sheriff", poor listener, distrustful ... conflictual when physician centered and directed, when pain is not validated, when pt is perceived as drug seeker (Esquibel \& Borkan, 2014)
a. Lack of education, limited guidelines
b. Lack of time
c. Inadequate assessment tools
d. Lack of empathy

\section{Opiate Dependency, Prescription Opioid Abuse (POA), Drug Abuse, with and without Pain}


"I took the pills like he (the doctor) told me to at first. And everything was fine, but I fell in love with the buzz. It makes you feel like a million bucks. It really does. Don't get me wrong, it took away the pain in my jaw, but the best part was that it took away your other pains too (Rigg \& Murphy, 2013).”

1. For opiate dependent individuals in methadone maintenance, contributions to good QOL include having social relationships, an occupation, good self image, being independent and having a meaningful life (DeMaeyer, et al, 2011) On the other hand, strong ambivalence exists - concern for withdrawal, limitations caused by opiate (now methadone) dependency including isolation, psychological problems, anxiety, discrimination.

a. Desire for Normalcy

b. Need for De-stigmatization

2. Harm Reduction and Abstinence as part of a continuum; aim by some for an opiate and methadone free life, while abstinence for some may not be realistic or desirable (DeMaeyer, et al, 2011)

a. Must have patient centered, individually tailored approach to care

b. Need for education

3. Contrasting perceptions and expectations by nurses and drug users of the therapeutic relationship - expectations by drug users that health care workers be non-judgmental and show compassion (McCreaddie, et al, 2010)

4. Drug use explained by the user as a side effect of other negative life events (McCreaddie, et al, 2010)...Need to give meaning to actions - especially hidden behaviors such as substance abuse (Rigg \& Murphy, 2013)...

5. Long standing hardship in childhood or adolescence leading to a "defining moment" that turned the individual down a path of substance abuse and addiction (Rigg \& Murphy, 2013).

6. Benefit in understanding which comes first - substance abuse or pain (St Marie, 2014).

7. Negative experiences: include feeling disbelieved, feeling stigmatized, health providers not providing care (St Marie, 2013). Positive experiences include success in sobriety, trust and confidence in the health care provider (St Marie, 2013).

a. Importance of looking at risk stratification

b. Importance of KNOWING THE PATIENT

c. Medicating non-pain symptoms with pain medication

d. Drugs at least initially "feel good"

e. Importance of supporting individuals when they are at a "defining moment"

8. A drug users routines and rituals must be followed in order to prevent withdrawal and manage pain... these rituals may be "illegal \& chaotic" (McCreaddie, et al, 2010).

a. Mutually exclusive rituals

9. Coexisting pain and substance use disorder can activate and potentiate the other, and drug craving may drive patients to deception (St Marie, 2013). 
a. "Reasons" for mistrust, self preservation or at least caution

10. Prescription opioids more desirable as an abusable agent as they are perceived as safer, purer, longer lasting and stronger (Rigg \& Murphy, 2013)

11. Older drug "abusers" needs may be different than those of younger substance abusers. They are at increased risk of morbidity, loneliness, stress, and anxiety (Roe, et al, 2010).

12. Drug use has a negative impact on health, qol, family relationships and social networks. Loss of key relationships... Encounters with death and dying are common and experienced at an earlier age for this group (Roe, et al, 2010)

13. Some see their own survival as resilience (Roe, et al, 2010).

a. Regret

b. Recognition of accelerated aging and health changes

c. Struggle with survival, death and dying

d. Importance of knowing the patient/knowing their story/individual needs

e. Importance of connecting with a patient's inner resilience

\section{Cancer Pain}

"I don't want to take too many pain killers. If I would always take pills as soon as it hurts a bit, I'd need a much higher dose in a few weeks. I am not going to do that... (Knudsen, et al., 2012)”

"I was really wondering about what caused the pain. What I feared most was probably that the cause was metastases...(Knudsen, et al., 2012)”

“Elders are hesitant to take narcotics. They aren't up front about it, but they won't take them. The older folks would rather suffer with the pain than feel they were out of touch with the earth/world. They don't like th hazy feeling (Hazous \& Knobf, 2013)." “I was sitting in the office and thinking, 'Oh dear God, please don't let it be someone where I have to sit and explain myself to him and start all over'(Luckett, et al, 2013).”

1. Cancer pain impacts all areas of life (Luckett, et al., 2013)

2. Cancer pain and treatment exist in a cultural and social context (Luckett, et al., 2013)

3. Patients are experts in their own pain management, (Luckett, et al., 2013)

a. Need for patient centeredness

4. Perceived lack of support by health professionals for non pharmacological and complementary and alternative pain management strategies (Luckett, et al., 2013)

a. Failure to identify patient goals

5. Opioids and opioid concern/opioids as a balancing act... concern that commencement of opioids represents worsening disease and death... a conflict for patients with increasing pain (Flemming, 2010).

6. Breakthrough pain in cancer as a unique phenomenon - acceptance that analgesics improve quality of life, but internal conflicts regarding opioids use and potential side effects - including masking the pain and fear of addiction (Weber, et al., 2011). 
a. Fear of the unknown

b. Pain as anxiety

c. Being a victim vs. being empowered

d. Recognizing the subjectivity of the experience

7. Pain management barriers: desire for privacy, fatalism, isolation, knowledge deficits, family as both helping and hindering (Hazous \& Knobf, 2013),

a. Importance of sensitive and culturally competent assessment and care of pain

b. Pain and pain management as culturally and individually defined

8. Anxiety over addiction (Flemming, 2010)

9. Use of and dependence on strong analgesics worrisome but at the same time concept of addiction less important to the patient in severe pain (Knudsen, et al., 2012).

10. Repeated instruction by health care workers regarding dependency and tolerance decreased patient concerns (Knudsen, et al., 2012).

11. Challenges coping with the side effects of pharmacological pain management (McPhearson, et al., 2014).

a. Importance of education

b. Importance of supporting function and self efficacy

12. Patients develop physical, practical and psychological strategies for coping with pain (Knudsen, et al., 2012); Cultural norms defining expression and treatment of both pain and cancer (Luckett, et al., 2013)

a. Must know the patient in order to support coping styles

13. Living with pain affects all aspects of life...Communicating and then finding a solution to pain (McPherson, et al., 2014).

14. Tradeoff between analgesia and the side effects of opiates becoming acceptable when pain is intolerable and death is perceived as imminent (Flemming, 2010).

a. Importance of goal setting and clarifying mutual expectations

15. Pain scales being difficult to use...Pain better described by storytelling (Hazous \& Knobf, 2013)

a. Importance of culturally appropriate pain scales/tools

b. Giving patients "permission" and education to use pain relief tools

16. Emotional Pain, family demands and stigma associated with opioid use (Hazous \& Knobf, 2013) Anger, frustration, sadness and despair, powerlessness, helplessness and loss of control (Knudsen, et al., 2012). Not wanting to use prescribed pain meds - desire for privacy, knowledge deficits, fatalism (Hazous \& Knobf, 2013).

a. Must anticipate needs/situations

b. Must be transparent in communication

17. Spiritual Pain, belief in causality, inability to participate in community and spiritual activities (Hazous \& Knobf, 2013)

a. Respect for cultural/spiritual practices 
18. Other consequences of pain include domains of duration, intensity, coping, physical and psychological function, as well as quality of sleep, (Knudsen, et al., 2012)

a. Duration and persistence of pain as draining

19. For most, previous experiences with pain are not relevant to the experience with cancer pain (Knudsen, et al., 2012)

a. Pain has different weight and meaning when attached to mortality

20. Severe pain as impairing cognitive function and concentration (Knudsen, et al, 2012)

a. Identifying goals of care and pain relief

b. Importance of self efficacy/control

21. Revealing and concealing pain to protect a caregiver or loved one, believing in pharmacological pain control as well as non pharmacological approaches, importance of knowing in order to identify pain (McPhearson, et al., 2014)

22. Pain is perceived as a significant problem for patients with cancer but inadequate pain management is common, with barriers of provider education and endorsement, cost and concerns about addiction - eventhough malignant pain is most often greatly improved with medical management (Simone, et al., 2012).

a. Trying to be a "good patient"

b. Importance of accurately assessing pain/knowing the patient - must be proactive, not reactive or passive

c. Education to be able to support both pharmacological and non pharmacological approaches and to facilitate teaching.

d. Openness and mutual transparency/honesty

e. Importance of a "common language" in describing pain - ongoing difficulty with pain scales.

23. May have sub optimal pain management until patient is referred to palliative or pain specialists (Weber, et al., 2011)

a. Education/knowing resources/team approach

b. Importance of expert knowledge

24. Need for "therapeutic alliance" between patient, family cg and health professionals and shared power and responsibility (Luckett, et al., 2013)

a. Pt/family centered approach

b. Interdisciplinary approach

\section{Nursing Perspective}

\section{A. End of Life and Illicit Drug Users}


"We kind of got caught off guard because our first client that got sick was quite young and experienced profound liver failure, extremely fast. He had to go to the hospital. He didn't want to but he had to. We didn't have any nursing support in place. We didn't have equipment. We didn'thave the drugs. He had to go to the hospital to die. It set us into our planning stage for the next event - getting equipment, nurses, drugs, aand all these things in place for the next person - Nurse Manager (McNeil et al., 2012).”

1. Nurses identify that barriers to end of life care services in this population include healthcare as a low priority, the mistrust of healthcare providers, "system" zero tolerance of illicit substances (McNeil \& Guirguis-Younger, 2011)

a. Need to know the patient/the story

2. Nursing intervention impacted by non- disclosure of drug use, concern for high levels of tolerance to palliate symptoms, challenges of care interruptions, and Nurse knowledge deficits about addiction and care of this population (McNeil \& GuirguisYounger, 2011).

a. Need for flexibility and seeing the greater good

3. Not realistic for this population to abstain from illicit drug use at end of life, thus harm reduction as approach to care for this population (McNeil \& Guirguis-Younger, 2011).

a. End of life care when there is addiction requires special knowledge and approaches to care

b. Goals of care must be individualized

4. Harm reduction supports improved access to palliative and support services (McNeil, et al., 2014). Harm reduction promotes openness in communication and improved health outcomes (McNeil, et al., 2014).

a. Knowing the patient/culture/currency

b. Poor educational preparation of the generalist to address these challenges effectively

c. Being open to harm reduction strategies

\section{B. Chronic Non-Cancer Pain (CNCP)}

"Disorganized system of care: e.g., having to hunt for narcotic keys, obtain co-signatures, find drugs, etc...Not knowing whether to believe the older patint's pain report or the family's perception of the person's pain instead...(Coker, et al., 2010)"

1. Patient related barriers: cognitive impairment, language barriers, sensory problems, pain reported to MD but not nurse, problems with using pain scales, willingness to bear pain, not wanting meds due to side effects (Coker, et al., 2010)

a. Need for nurse to really know the patient

b. Must promote change to overcome system and knowledge deficits

c. Pain scales must be meaningful 
2. Systems barriers: inadequate time for patient teaching, inadequate time for non pharmacologic pain relief, non pharmacological pain measures not available, disorganized care system (Coker, et al., 2010)

a. The discrepancy between the nurse "knowing" and the nurse "doing"

b. Making time for optimal care

c. Need for continual organizational support and reinforcement of "best practices" with regard to pain assessment and management

3. Fear of over medicating (Coker, et al., 2010)

a. Knowledge deficits

\section{Opiate Dependency, Prescription Opioid Abuse (POA), Drug Abuse, with and without} Pain

"I think some of the nursing staff think 'well why am I bothering? I'm trying my best here and you're doing something like that' - or you've got the guy who broke his ankle and walked on it straight away. You know he was walking on it, but he would not listen...(Mcreaddie, et al, 2010)”

1. Connecting with drug users "as people not problems" (McCreaddie, et al, 2010)

a. Knowing the patient

2. Contrasting expectations and perceptions of the therapeutic relationship...struggle with moral relativism (McCreaddie, et al., 2010)

3. Generalist nurses may have stereotypical ideas of patients with opiate dependency DeMaeyer, et al., 2011)

a. Knowledge deficits regarding pain, addiction, dependency

4. Nurses must demonstrate psychosocial support and positive interactions - but may perceive drug users as immoral, responsible for their health outcomes (DeMaeyer, et al., 2011)

a. Education to counter deep seated personal biases

b. Knowing but not doing

5. The routines and rituals of nursing as organized and efficient, authoritative and in control may be at odds with the rituals and routines of drug users (DeMaeyer, et al., 2011).

a. Potential for mutually exclusive rituals and routines for nurses and drug users

6. Nurses must have system support to develop professional skills and attitudes and create a positive environment to care for this population (DeMaeyer, et al., 2011)

a. What does effective care of this population look like?

b. Harm Reduction approach

c. Need for mentoring and leadership that model effective care of this population

d. Knowledge deficits regarding pain, addiction, dependency

\section{Cancer Pain Management}


"If the doctor would just listen to my opinion...it's frustrating if the patient is in pain and the doctor is not willing to prescribe the medication...(Luckett, et al., 2013)."

"I perceive my role as primarily to educate, and then to empower, and then to act as an advocate (Luckett, et al., 2013).”

"You definitely have to have teamwork up here. If you don't have teamwork, nothing will go on (Luckett, et al., 2013).”

1. Nurses play major role in cancer pain management (Flemming, 2010)

2. Nurses feel relieved when patient pain is relieved (Flemming, 2010)

a. Pain management is different when there is grave illness

3. Expectation by patients that nurse be a caring individual (Luckett, et al., 2013)

4. Hierarchy of the medical system and rigid roles have negative impact on teamwork and pain management- nurses feeling that they are not always heard - yet most all place a value on teamwork - but operationalization is needed (Luckett, et al., 2013)

a. Need for patient centered, collegial/team approach

b. Knowing but not doing

5. Encounters with patients' Existential Pain - leading to feelings of powerlessness, insufficiency and uncertainty when facing death and dying vs. development of open and close therapeutic relationship with patient and family (Browall, et al., 2014)

a. Having the courage to be truly present

6. The value of listening to patient stories, helping patients summarize and reflect about their lives, and through this, gaining insight into patients 'existential needs (Browall, et al., 2014)

a. Having the courage and taking the time to know the patient, while remaining therapeutic

b. End of life care must be comprehensive with an interdisciplinary team

7. Balancing honesty with not telling the "whole truth" (Browall, et al., 2014)

a. Preserving hope

8. Feeling responsible for assessing that home environment is safe from substance abuse or diversion (Flemming, 2010)

a. Mistrust

b. Gatekeeper role

\section{E. End of Life and Pain}

“...sometimes it does not seem like the physician is listening to what I am saying... I am the one closest to the patient... and assessing them all day...(Jablonski \& Duke, 2012).”

“...Families will not ask patients if they are hurting... because they don't want the patient sedated where they will not be able to interact with them ...family members want their loved ones to be comfortable, but not always to the point of unresponsive... want to spend the last days...hoping that the patient can respond right up until death...(Jablonski \& Duke, 2012)." 
"Nursing Home nurses are health care professionals but many are scared of giving morphine and causing a patient's demise...or afraid to 'get the patient addicted', or that they will make the patient 'all drugged up'...for some, they don't want morphine in their home because they have family members with substance abuse problems (Lau, et al., 2010).”

1. Barriers to effective pain management include limited knowledge, skills \& experience, judgmentalism, conflicts, time waiting for orders, authoritative boundaries, and fears of addiction and accidental overdose, fear of litigation (Jablonski \& Duke, 2012).

a. Need for patient centered care

2. Facilitators of effective pain management include education, individualized care and use of specialty services (Jablonski \& Duke, 2012)

a. Goal setting

b. communication

3. Despite awareness, inadequate pain management persists and there has been little in the way of incorporating knowledge, attitudes and practice (Jablonski \& Duke, 2012).

a. Discrepancies between "knowing" and "doing"

4. Effective communication between physicians, nurses patients and families is critical (Jablonski \& Duke, 2012) must establish trust, provide information, promote self confidence, offer relief and evaluate understanding (Lau, et al., 2012)

a. Importance of interdisciplinary care

b. Importance of coordinating with all the stakeholders

\section{Provider/Prescriber/Physician Perspective}

\section{A. Chronic Non Cancer Pain (CNCP)}

“...because if you've dealt with any of these patients, then you'll know they're the most irritant substance on the planet from any others...I would hope that I would give them the best medical care I could, but I'm not prepared to sit and be manipulated by them - Pain Specialist - (Baldacchino, et al, 2010)."

“...they take up an inordinate amount of time...trying to address what the pain is and the causes for it takes up an inordinate amount of time...this is why you have to limit the number, you cant carry a lot of them because there's so much paperwork...(Barry, et al, 2010).”

1. Opioids have a useful place for some patients with CNCP (Baldacchino, et al., 2010) but chronic opioids use is not preferred modality (Esquibel \& Borkan, 2014) not first line treatment (Spitz, et al., 2011)

2. Harm of using opioids outweighs potential benefits for CNCP (Spitz, et al., 2011)

3. Treatment of chronic pain as frustrating (Spitz, et al., 2011) 
4. "Opiophobia" present for many General Practitioners (Baldacchino, et al., 2010), a "confounding concern" for first year medical students (Corrigan, et al., 2011) vs. feeling pressure to prescribe opiates (Matthias, et al., 2010)

5. Not wanting to prescribe opiates to people with known history of substance use disorder/not wanting to "feed the habit" (Baldacchino, et al., 2010)

6. Looking for drug seeking behaviors e.g. lost prescriptions, early medication request, prescriber/pharmacy shopping (Baldacchino, et al., 2010)

7. Awareness of patient reluctance to reveal drug use (Baldacchino, et al., 2010)

8. Absence of objective measures of pain (Barry, et al., 2010) Difficult to accept and treat nonobjective pain (Esquibel \& Borkan, 2014)

a. Frustration

b. Ineffective pain assessment tools and guidelines

9. Lack of awareness/interest/expertise in treating CNCP or prescribing opiates and the combined co-occurrence of psychiatric disorders and addiction (Barry, et al., 2010), lack of willingness to utilize harm reduction interventions (Butler \& Sheridan, 2010) lack of confidence in treating pain (Esquibel \& Borkan, 2014)

a. Knowledge deficits

10. Treating pain may not be seen as top health priority (Esquibel \& Borkan, 2014)

11. Limited referral options, limited insurance coverage, limited knowledge about the patient, limited time (Barry, et al., 2010)

12. No unified picture of a "typical" drug seeker - but two main typologies: the "abuser" and the "overuser"(Butler \& Sheridan, 2010)

13. Aberrant drug use seen as a covert activity (Butler \& Sheridan, 2010)

a. Mutual mistrust

14. Pain as a biopsychosocial model (Esquibel \& Borkan, 2014)

a. Objectivity vs subjectivity

15. Facilitators include patient $\&$ family education, using risk assessment tools, finding peer support, education regarding dosing (Spitz, et al., 2011).

16. Ongoing education in pain management and specialty roles should be mandatory regardless of specialty, residents felt unprepared to treat CNCP (Yanni, et al., 2010).

17. Shared findings of other studies that providers often underestimate pain (Yanni, et al., 2010)

18. Excessive time needed for patients with chronic pain who often have co-morbid psychiatric conditions (Yanni, et al., 2010)

a. The system does not support appropriate reimbursement for the care and monitoring of the $\mathrm{CNCP}$ population

b. Compassion fatigue and burn out

19. Conversation may be the best pain assessment tool, patient centered communication, empathy and shared decision making (Matthias, et al., 2010). Opioid agreements - one 
prescriber, no change in dosing, no early refills, random drug testing (Schneider \& Kirsch, 2010).
a. Knowing the patient
b. Need for education
c. Mutual trust

\section{B. Cancer Pain Management}

"We are bombarded by guidelines which are not based on evidence and the local hospitals do it and send them out to us. It just creates confusion...(Luckett, et al., 2013)." "I've seen cancer patients for years that should never have been in the pain they were in and people were afraid they were going to get addicted or die so they didn't treat them appropriately...(Luckett, et al., 2013).”

"If you can't find that pathophysiologic connection, the question then becomes, 'is the pain real or not?'(Luckett, et al., 2013)."

1. Pain relief perceived as equating to improved mood and function (Bhatia, et al, 2014)

2. Pain relief perceived as fewer breakthrough doses needed (Bhatia, et al., 2014)

3. While pt goals and goals of pain management are seen as important, they were not often identified (Bhatia, et al., 2014).

a. Knowing but not doing

b. Not really knowing the patient

4. Difficulty judging treatment response by pain scales (Bhatia, et al., 2014); preference of using objective and subjective pain indicators... desire to verify that pain is as severe as reported (Luckett, et al., 2013).

a. Ineffectiveness of standard pain scales

5. Dissatisfaction with existing clinical guidelines (Luckett, et al., 2013)

6. Existential meaning of cancer \& cancer pain - pain is about the patient (Flemming, 2010)

7. Intersubjectivity of pain (Flemming, 2010)

8. Teamwork required to successfully treat pain (Flemming, 2010).

9. Fears around addiction explicitly or implicitly communicated to patients (Flemming, 2010)

10. Fears around diversion (Flemming, 2010)

11. Time limitations and workload leading to rushed encounters (Luckett, et al., 2013)

12. Taking the success or failure of pain management strategies personally (Luckett, et al., 2013)

\section{End of Life and Pain}


"I realized that it's $O K$ to listen to the patient when they say they are hurting. I also learned the importance of validating the feelings of someone who is suffering (Corrigan, et al, 2010)."

"Being on opiates might mean that the patient is near death, that I am giving up on them, or that they themselves are giving up (Zerzan, et al.,, 2010."

"Listening to patients talk about their pain and suffering all day is exhausting. It is so draining to listen and be empathetic...and then you get patients with whom you don't want to be empathetic. You don't ike them that much and you still have to ccare and you still have to listen...I don't know that I want to care that much (Corrigan, et al, 2010)."

1. Pain as a concern to first year medical students (Corrigan, et al., 2011)

2. Encounters with acute, chronic, end of life, iatrogenic and emotional pain were mostly negative for first year medical students in primary care setting (Corrigan, et al., 2011)

a. Medical education must include tools to address pain no matter what the specialty

3. Multidisciplinary team as essential to facilitating opioid prescribing and providing effective EOL care (Gardiner, et al., 2012).

4. Health professionals in primary care lack confidence in prescribing opioids (Gardiner, et al., 2012).

5. Improved guidelines for EOL opioid prescribing are needed for the general practitioner (Gardiner, et al., 2012)

6. Social meaning of opiates and personal experiences with opiates, whether or not patient has history of substance abuse and diagnosis drive prescribing (Zerzan, et al., 2011)

7. Barriers include restrictive policies, institutional barriers, concerns for addiction or misuse, fear of the DEA, history of disciplinary action (Zerzan, et al., 2011)

8. EOL opiates may hold a different social meaning to the prescriber, the patient and the family (Zerzan, et al., 2011)

\section{Caregiver Perspective}

\section{A. Cancer Pain Management}

"The hardest part is watching the mind go and the body waste. Bone cancer is so painful, will my mother go into a coma? Will the pain be controlled as we have been promised? (Luckett, et al., 2013)."

"They should really treat you as someone other than the person who drove the car (Luckett, et al, 2013)."

“It's not a sense of duty. I don't think that would be the right way to put it. It's just something that seems to be filling something inside of me (Luckett, et al., 2013)."

1. Family as helping and hindering pain management (Hazous \& Knobf, 2013). Conflict between supporting patient choices and doing what's "best" (Luckett, et al., 2013)

2. Potential for family caregivers to feel marginalized, but at the same time they play an important role in monitoring and management of pain and pain interventions (Luckett, et al., 2013). 
3. Communicating pain and finding a solution - changing roles as patient declines (McPherson, et al., 2014)

4. The caregiver can be seen as both the recipient and co-provider of care (Meeker, et al., 2011)

5. Caregivers are more likely to use pharmacological approaches to pain, while non pharmacological approaches are patient preference (McPherson, et al., 2014)

6. Successful pain management must include the family caregiver - and accuracy of caregiver knowledge was associated with lower pain in the patient (Meeker, et al., 2011)

\section{B. EOL Pain Management}

“....she has chronic pain...the morphine was in an unusual bottle and I was afraid to giver her too much or too little and the dropper wasn't working. It was very scary...(Kelley, et al., 2013)."

1. Concurrent responsibilities- work outside the home, caring for other ill family members, financial burden (Kelley, et al., 2013)

2. Fears of over/under medicating patient (Kelley, et al., 2013)

3. Knowledge deficits regarding EOL symptom management (Kelley, et al., 2013)

a. Nothing substitutes for really knowing the patient and family

b. Anticipating and educating about disease progression and symptom management

c. Need to individualize pain and symptom management and to titrate to effect

4. Caregiver "owning the setting", mistrust of interventions and perceiving that they know what's best, differences in priorities and abilities (Lau, et al., 2010)

a. Importance of goal setting

b. Importance of interagency and interpersonal communication

c. Taking the time to coordinate all stakeholders

5. Poor communication and disagreements among caregivers along with overwhelming responsibility (Lau, et al., 2010)

\section{Societal Perspective}

\section{A. Cancer Pain Management}

Regarding morphine use in cancer care "ease the soul"... "relax"... "provide peace"... “ease the journey"(Grant, et al., 2015)

1. Opiates and cancer pain hold notable social meanings built on meanings taken from film, media, historical beliefs, and personal experience (Grant, et al., 2015)

2. Societal acceptance in use of opiate to treat cancer pain - helps patient achieve peace and control (Grant, et al., 2015) 
3. Community perspective of use of opiates in cancer pain management are different than myths commonly seen - barriers may be more reflective of the views of health professionals (Grant, et al., 2015)

4. Health professionals should have controlled, responsible prescribing of opiates (Grant, et al., 2015) 


\section{Appendix B}

\section{Truly Knowing the Patient}

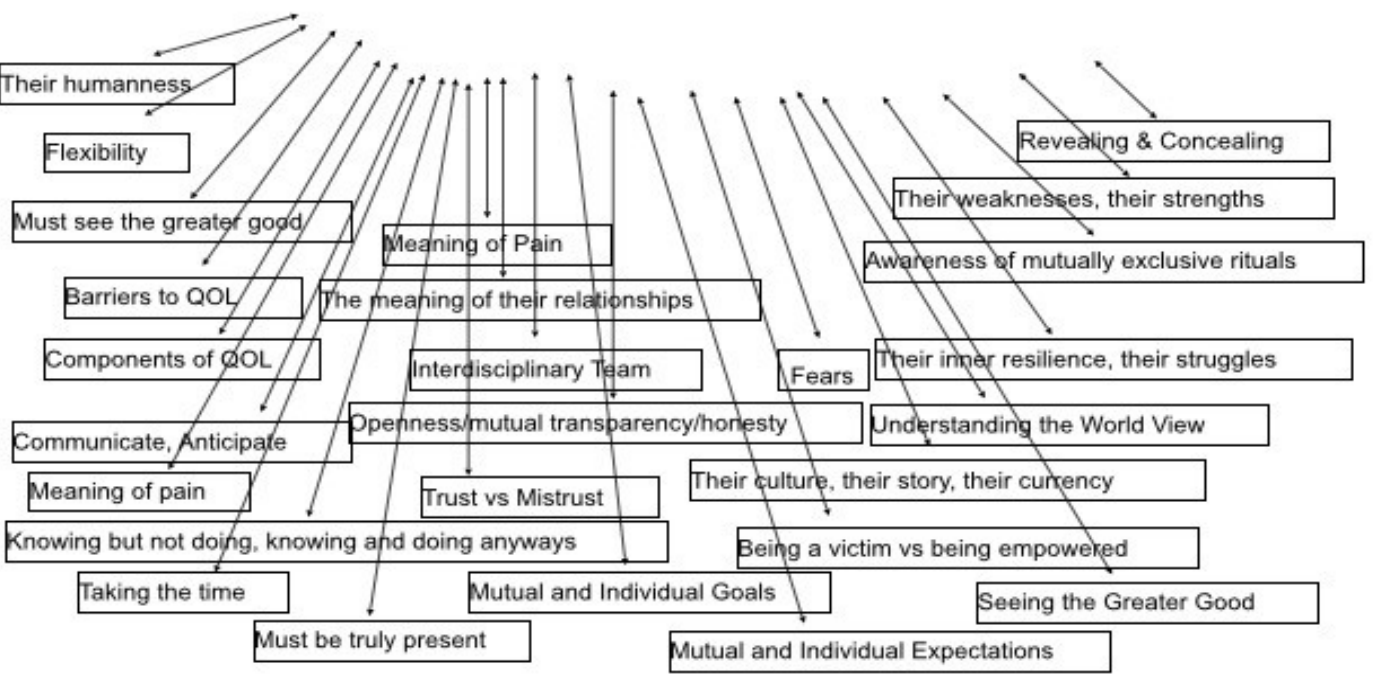

Figure 1. "Truly Knowing the Patient" captures the significant characteristics of the patientclinician interaction from synthesis and interpretation of the qualitative literature. 


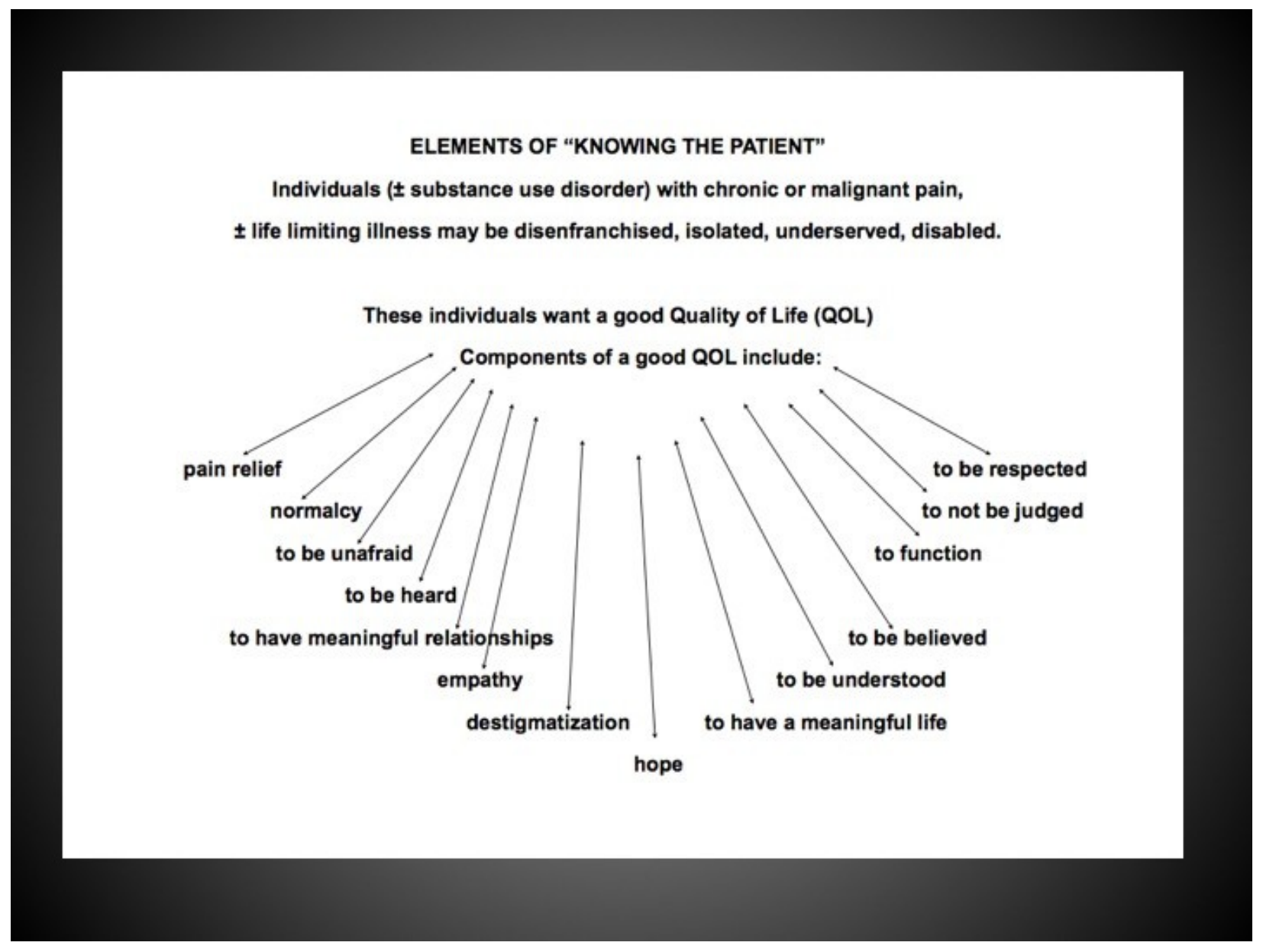

Figure 2. Components of a Good Quality of Life, a sub theme of Knowing the Patient, identifies the characteristics of a what the individual with pain (whether or not there is SUD or life limiting illness) considers necessary for good QOL as found in synthesis and interpretation of the qualitative literature utilized in this project. 


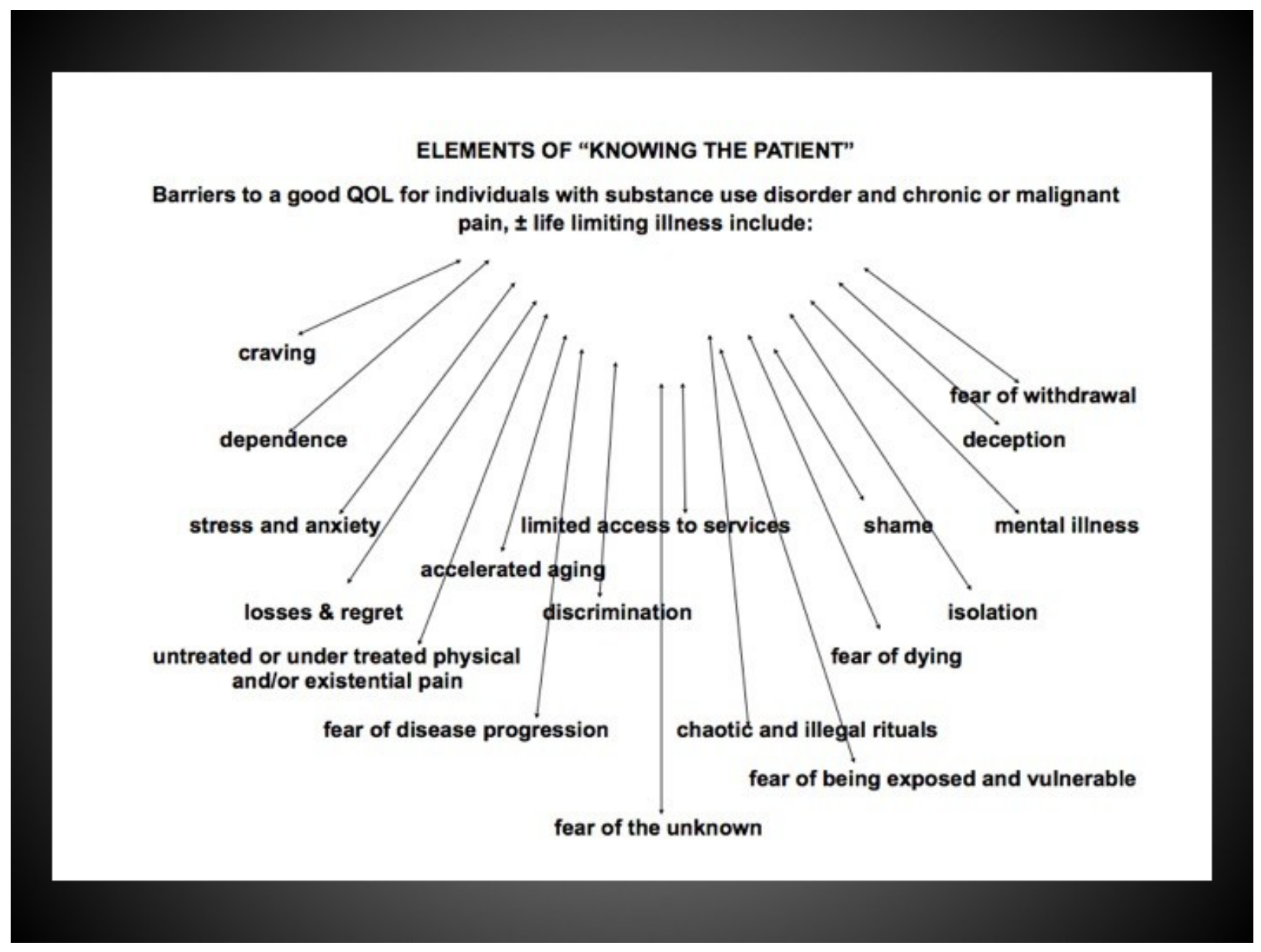

Figure 3. Barriers to a Good Quality of Life, a sub theme of Knowing the Patient, identifies the characteristics of a what the individual with SUD and pain (whether or not there is life limiting illness) consider to be barriers to a good QOL as found in the synthesis and interpretation of the qualitative literature utilized in this project. 


$\begin{aligned} & \text { Patient } \\ & \text { Perspective }\end{aligned}$
$\begin{aligned} & \text { fear of the unknown } \\ & \text { fear of core being } \\ & \text { exposed and } \\ & \text { vulnerable } \\ & \text { fear of pain }\end{aligned}$
$\begin{aligned} & \text { fear of being judged } \\ & \text { fear of withdrawal } \\ & \text { fear of cravings }\end{aligned}$

Figure 4. Fears from the perspectives of Patient, Nurse, Provider/Prescriber and Caregiver as identified by the synthesis and interpretation of the qualitative literature utilized in this project. 


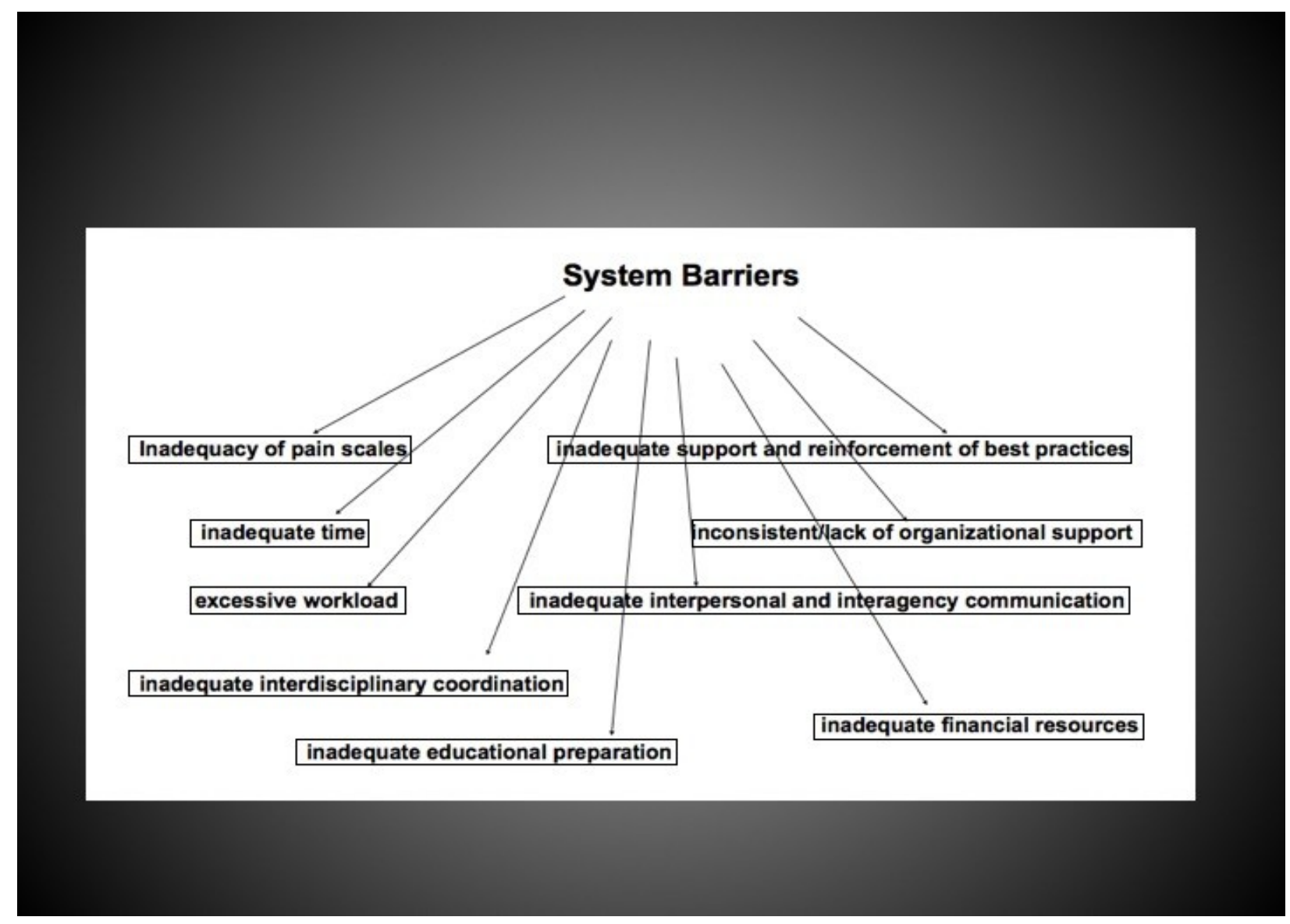

Figure 5. System Barriers to pain assessment and management and "knowing the patient" as identified by the synthesis and interpretation of the qualitative literature utilized in this project. 


\section{References}

Al Khalaileh, M., \& Al Qadire, M. (2012). Barriers to cancer pain management: Jordanian nurses' perspectives. International Journal Of Palliative Nursing, 18(11), 535-540.

American Academy of Pain Medicine (n.d.). AAPM facts and figures on pain.Retrieved from: http://www.painmed.org/patientcenter/facts_on_pain.aspx\#overview

American Psychiatric Association, \& American Psychiatric Association. (2013). Highlights of changes from DSM-IV-TR to DSM-5. Arlington, VA: American Psychiatric Association.

Anderson J. Nursing management of the cancer patient in pain: a review of the literature. Cancer Nursing [serial online]. February 1982;5:33-41. Available from: CINAHL Plus with Full Text, Ipswich, MA.

Baldacchino, A., Gilchrist, G., Fleming, R., \& Bannister, J. (2010). Guilty until proven innocent: A qualitative study of the management of chronic non-cancer pain among patients with a history of substance abuse. Addictive behaviors, 35(3), 270-272.

Barclay, J. , Owens, J. , \& Blackhall, L. (2014). Screening for substance abuse risk in cancer patients using the opioid risk tool and urine drug screen. Supportive Care in Cancer, $22(7), 1883-1888$.

Barry, D. T., Irwin, K. S., Jones, E. S., Becker, W. C., Tetrault, J. M., Sullivan, L. E., ... \& Fiellin, D. A. (2010). Opioids, chronic pain, and addiction in primary care. The Journal of Pain, 11(12), 1442-1450.

Baumrucker, S. J., Carter, G. T., VandeKieft, G., Stolick, M., Harrington, D., Sheldon, J. E., \& Morris, G. M. (2009). Diversion of Opioid Pain Medications at End-of-Life: Ethics Roundtable. American Journal of Hospice and Palliative Medicine. 
Beck, C. T. (2009). Metasynthesis: A goldmine for evidence-based practice. AORN journal, 90(5), 701-710.

Bell, K., \& Salmon, A. (2009). Pain, physical dependence and pseudoaddiction: Redefining addiction for 'nice'people?. International Journal of Drug Policy, 20(2), 170-178.

Bhatia, R, Jane, G., Karen, F., \& Colette, R. (2014). "We all talk about it as though we're thinking about the same thing." Healthcare professionals' goals in the management of pain due to advanced cancer: a qualitative study. Supportive Care in Cancer, 22(8), 20672073.

Blackhall, L. J., Alfson, E. D., \& Barclay, J. S. (2013). Screening for substance abuse and diversion in Virginia hospices. Journal of palliative medicine, 16(3), 237-242.

Blay, N., Glover, S., Bothe, J., Lee, S., \& Lamont, F. (2012). Substance users' perspective of pain management in the acute care environment. Contemporary nurse, 42(2), 289-297.

Blobaum, P. M. (2013). Mapping the literature of addictions treatment. Journal of the Medical Library Association: JMLA, 101(2), 101.

Blayney, D. W., Severson, J., Martin, C. J., Kadlubek, P., Ruane, T., \& Harrison, K. (2012). Michigan oncology practices showed varying adherence rates to practice guidelines, but quality interventions improved care. Health Affairs, 31(4), 718-728.

Butler, R., \& Sheridan, J. (2010). Innocent parties or devious drug users: the views of primary healthcare practitioners with respect to those who misuse prescription drugs. Harm reduction journal, $7(1), 21$.

Childers, J. W., \& Arnold, R. M. (2012). "I Feel Uncomfortable 'Calling a Patient Out"”: Educational Needs of Palliative Medicine Fellows in Managing Opioid Misuse. Journal of pain and symptom management, 43(2), 253-260. 
Cipriano, P. F. (2015). Fighting fear. American Nurse, 47(1), 3.

Coker, E., Papaioannou, A., Kaasalainen, S., Dolovich, L., Turpie, I., \& Taniguchi, A. (2010). Nurses' perceived barriers to optimal pain management in older adults on acute medical units. Applied Nursing Research, 23(3), 139-146.

Compton, P. (2011). Treating chronic pain with prescription opioids in the substance abuser: Relapse prevention and management. Journal of Addictions Nursing, 22(1-2), 39-45.

Corrigan, C., Desnick, L., Marshall, S., Bentov, N., \& Rosenblatt, R. A. (2011). What Can We Learn from First-Year Medical Students' Perceptions of Pain in the Primary Care Setting?. Pain Medicine, 12(8), 1216-1222.

De Maeyer, J., Vanderplasschen, W., Camfield, L., Vanheule, S., Sabbe, B., \& Broekaert, E. ( 2011). A good quality of life under the influence of methadone: A qualitative study among opiate-dependent individuals. International Journal of Nursing Studies, 48(10), 1244-1257.

Dev, R. , Parsons, H. , Palla, S. , Palmer, J. , Del Fabbro, E. , et al. (2011). Undocumented alcoholism and its correlation with tobacco and illegal drug use in advanced cancer patients. Cancer, 117(19), 4551-4556.

DuBois, J. C., \& Reed, P. G. (2014). The Nurse Practitioner and Policy in End-of-Life Care. Nursing science quarterly, 27(1), 70-76.

Dzul-Church, V., Cimino, J. W., Adler, S. R., Wong, P., \& Anderson, W. G. (2010). “I'm Sitting Here By Myself...”: Experiences of Patients with Serious Illness at an Urban Public Hospital. Journal of Palliative medicine, 13(6), 695-701. 
Edlund, M. J., Martin, B. C., Devries, A., Fan, M. Y., Braden, J. B., \& Sullivan, M. D. (2010). Trends in use of opioids for chronic non-cancer pain among individuals with mental health and substance use disorders: the TROUP study. The Clinical journal of pain, $26(1), 1$.

Eriksen, J., Sjøgren, P., Bruera, E., Ekholm, O., \& Rasmussen, N. K. (2006). Critical issues on opioids in chronic non-cancer pain:: An epidemiological study. Pain, 125(1), 172-179.

Esquibel, A. Y., \& Borkan, J. (2014). Doctors and Patients in Pain: Conflict and Collaboration in Opioids Prescription in Primary Care. PAIN

Eyler, E. C. (2013). Chronic and acute pain and pain management for patients in methadone maintenance treatment. The American Journal on Addictions, 22(1), 75-83.

Ferrell, B. (2005). Ethical perspectives on pain and suffering. Pain Management Nursing. 6(3), 83-90.

Fine, R. L. (2007). Ethical and practical issues with opioids in life-limiting illness. Proceedings (Baylor University. Medical Center), 20(1), 5.

Fineberg, I., Wenger, N., \& Brown-Saltzman, K. (2006). Unrestricted opiate administration for pain and suffering at the end of life: knowledge and attitudes as barriers to care. Journal Of Palliative Medicine, 9(4), 873-883

Fishman, S. , Young, H. , Lucas Arwood, E., Chou, R. , Herr, K. , et al. (2013). Core competencies for pain management: Results of an interprofessional consensus summit. Pain Medicine, 14(7), 971-981. 
Flemming, K., Adamson, J., \& Atkin, K. (2008). Improving the effectiveness of interventions in palliative care: the potential role of qualitative research in enhancing evidence from randomized controlled trials. Palliative medicine, 22(2), 123-131.

Flemming, K. (2010). The use of morphine to treat cancer-related pain: a synthesis of quantitative and qualitative research. Journal of pain and symptom management, 39(1), $139-154$.

Fletcher, D.S., \& Panke, J.T. (2012). Opportunities and challenges for palliative care professionals in the age of health reform. Journal of Hospice and Palliative Nursing.14(7), 452-459.

Gaertner, J. , \& Schiessl, C. (2013). Cancer pain management: What's new?. Current Pain and Headache Reports, 17(4), 1-9.

Gardiner, C., Gott, M., Ingleton, C., Hughes, P., Winslow, M., \& Bennett, M. I. (2012). Attitudes of health care professionals to opioids prescribing in end-of-life care: a qualitative focus group study. Journal of pain and symptom management, 44(2), 206-214

Garland, E. L., Froeliger, B., Zeidan, F., Partin, K., \& Howard, M. O. (2013). The downward spiral of chronic pain, prescription opioid misuse, and addiction: Cognitive, affective, and neuropsychopharmacologic pathways. Neuroscience \& Biobehavioral Reviews, 37(10), $2597-2607$.

Gifford, W. A., Graham, I. D., \& Davies, B. L. (2013). Multi-level barriers analysis to promote guideline based nursing care: a leadership strategy from home health care. Journal Of Nursing Management, 21(5), 762-770. doi:10.1111/jonm.12129

Giovanni, L. A. (2012). End-of-Life Care in the United States: Current Reality and Future 
Promise - A Policy Review. Nursing Economic\$, 30(3), 127-135.

Goldstein, N., \& Fischberg, D. (2008). Update in palliative medicine. Pain mana gement.

[Commentary on] Systemic administration of local anesthetics to relieve neuropathic

pain: a systematic review and meta-analysis. Annals Of Internal Medicine, 148(2), 135136.

Goebel, J. R., Sherbourne, C. D., Asch, S. M., Meredith, L., Cohen, A. B., Hagenmaier, E., ... \& Lorenz, K. A. (2010). Addressing patients' concerns about pain management and addiction risks. Pain Management Nursing, 11(2), 92-98.

Gourlay, D. , Heit, H. , \& Almahrezi, A. (2005). Universal precautions in pain medicine: A rational approach to the treatment of chronic pain. Pain Medicine, 6(2), 107-112.

Gourlay, D. L., \& Heit, H. A. (2009). Universal precautions revisited: managing the inherited pain patient. Pain Medicine, 10(S2), S115-S123.

Grant, M., Ugalde, A., Vafiadis, P., \& Philip, J. (2014). Exploring the myths of morphine in cancer: views of the general practice population. Supportive Care in Cancer, 1-7.

Haozous, E. A., \& Knobf, M. T. (2013). “All My Tears Were Gone”: Suffering and Cancer Pain in Southwest American Indians. Journal of pain and symptom management, 45(6), 10501060.

Head, B. (2011). Twilight ethics: dilemmas at the end of life. Topics in Geriatric Rehabilitation, $27(1), 53-61$.

Healthy People 2020, retrieved from:

http://healthypeople.gov/2020/1hi/substanceabuse.aspx?tab=overview last updated 6/6/13. 
Herr, K., Titler, M., Fine, P. G., Sanders, S., Cavanaugh, J. E., Swegle, J., ... \& Forcucci, C. (2012). The Effect of a Translating Research into Practice (TRIP)-Cancer Intervention on Cancer Pain Management in Older Adults in Hospice. Pain Medicine, 13(8), 1004-1017. Institute of Medicine of the National Academies, no author (released 6/29/11) retrieved from:

http://www.iom.edu/Reports/2011/Relieving-Pain-in-America-A-Blueprint-forTransforming-Prevention-Care-Education-Research/Report-Brief.aspx.

Jablonski, K., \& Duke, G. (2012). Pain Management in Persons Who Are Terminally Ill in Rural Acute Care: Barriers and Facilitators. Journal of Hospice \& Palliative Nursing, 14(8), 533-540.

Kelley, M., Demiris, G., Nguyen, H., Oliver, D. P., \& Wittenberg-Lyles, E. (2013). Informal hospice caregiver pain management concerns: A qualitative study. Palliative medicine, 0269216313483660 .

Joint Commission, no author(2014). Facts about pain management. Retrieved from: http://www.jointcommission.org/pain management/

Kehl, K. , \& McCarty, K. (2011). Does sharing research data with participating hospices affect practice?. Journal of Palliative Medicine, 14(2), 147-151.

King, S. J., Reid, C., Forbes, K., \& Hanks, G. (2011). A systematic review of oxycodone in the management of cancer pain. Palliative medicine, 25(5), 454-470.

Kirsh, K. L., \& Passik, S. D. (2006). Palliative care of the terminally ill drug addict. Cancer investigation, 24(4), 425-431.

Kirsh, K. L., \& Smith, H. S. (2008). Special issues and concerns in the evaluation of older adults who have pain. Clinics in geriatric medicine, 24(2), 263-274. 
Knudsen, A., Aass, N., Fainsinger, R., Caraceni, A., Klepstad, P., Jordhøy, M., \& ... Kaasa, S. (2009). Classification of pain in cancer patients--a systematic literature review. Palliative Medicine, 23(4), 295-308. doi:10.1177/0269216309103125

Koyyalagunta, D., Bruera, E., Aigner, C., Nusrat, H., Driver, L., \& Novy, D. (2013). Risk Stratification of Opioid Misuse among Patients with Cancer Pain Using the SOAPP-SF. Pain Medicine, 14(5), 667-675.

Krashin, D., Murinova, N., \& Ballantyne, J. (2012). Management of pain with comorbid substance abuse. Current psychiatry reports, 14(5), 462-468.

Lau, D., Masin-Peters, J., Berdes, C., \& Ong, M. (2010). Perceived barriers that impede provider relations and medication delivery: hospice providers' experiences in nursing homes and private homes. Journal Of Palliative Medicine, 13(3), 305-310.

doi:10.1089/jpm.2009.0283

Lau, D. T., Joyce, B., Clayman, M. L., Dy, S., Ehrlich-Jones, L., Emanuel, L., ... \& Shega, J. W. (2012). Hospice providers' key approaches to support informal caregivers in managing medications for patients in private residences. Journal of pain and symptom management, 43(6), 1060-1071

Lee, H. S., \& Zerai, A. (2010). "Everyone deserves services no matter what": Defining success in harm-reduction-based substance user treatment. Substance use \& misuse, 45(14), 2411-2427.

Lembke, A. (2012). Why doctors prescribe opioids to known opioid abusers. New England Journal of Medicine, 367(17), 1580-1581. 
Letizia, M., Creech, S., Norton, E., Shanahan, M., \& Hedges, L. (2004). Barriers to caregiver administration of pain medication in hospice care. Journal Of Pain \& Symptom Management, 27(2), 114-124

Ling, W., Mooney, L., \& Hillhouse, M. (2011). Prescription opioid abuse, pain and addiction: clinical issues and implications. Drug and alcohol review, 30(3), 300-305.

Lorenz, K., Lynn, J., Dy, S., Shugarman, L., Wilkinson, A., Mularski, R., \& ... Shekelle, P. (2008). Clinical guidelines. Evidence for improving palliative care at the end of life: a systematic review. Annals Of Internal Medicine, 148(2), 147-159.

Luckett, T., Davidson, P. M., Green, A., Boyle, F., Stubbs, J., \& Lovell, M. (2013). Assessment and management of adult cancer pain: a systematic review and synthesis of recent qualitative studies aimed at developing insights for managing barriers and optimizing facilitators within a comprehensive framework of patient care. Journal of pain and symptom management, 46(2), 229-253.

Matteliano, D., Marie, B. J. S., Oliver, J., \& Coggins, C. (2014). Adherence Monitoring with Chronic Opioid Therapy for Persistent Pain: A Biopsychosocial-Spiritual Approach to Mitigate Risk. Pain Management Nursing, 15(1), 391-405.

Matthias, M. S., Krebs, E. E., Collins, L. A., Bergman, A. A., Coffing, J., \& Bair, M. J. (2013). "I'm Not Abusing or Anything": Patient-physician communication about opioids treatment in chronic pain. Patient education and counseling, 93(2), 197-202.

McCaffery, M. (1990). Nurses lead the way to new priorities. American Journal of Nursing, $90(10), 45$.

McCaffery, M. (1991). Pain control battle. The American Journal of Nursing, 91(11), 15. 
McCaffery, M. (1992). Pain control - barriers to the use of available information. CANCER, $70(5), 1438-1449$

McCaffery, M. (1995). Opioids, addiction, and the terminally ill. American Journal of Nursing, $95(4), 61$.

McCaffrey, M., \& Ferrell, B. R. (1997). Nurses' knowledge of pain assessment and management: How much progress have we made? Journal of pain and symptom management, 14(3), $175-188$.

McCaffery, M (2011). Misconceptions that hamper assessment and treatment of patients who report pain. In Pasero, C., \& McCaffery, M. (Eds.). Pain assessment and pharmacologic management. (20-47) Mosby Elsevier: St Louis.

McCreaddie, M., Lyons, I., Watt, D., Ewing, E., Croft, J., Smith, M., \& Tocher, J. (2010). Routines and rituals: A grounded theory of the pain management of drug users in acute care settings. Journal of Clinical Nursing, 19(19-20), 2730-2740.

McNeil, R., Dilley, L. B., Guirguis-Younger, M., Hwang, S. W., \& Small, W. (2014). Impact of supportive care facility for people living with HIV/AIDS: a qualitative study. Journal of the International AIDS Society, 17(1).

McNeil, R., \& Guirguis-Younger, M. (2012). Illicit drug use as a challenge to the delivery of end-of-life care services to homeless persons: Perceptions of health and social services professionals. Palliative medicine, 26(4), 350-359.

McNeil, R., Guirguis-Younger, M., Dilley, L. B., Aubry, T. D., Turnbull, J., \& Hwang, S. W. (2012). Harm reduction services as a point-of-entry to and source of end-of-life care and support for homeless and marginally housed persons who use alcohol and/or illicit drugs: a qualitative analysis. BMC public health, 12(1), 312. 
McPherson, C. J., Hadjistavropoulos, T., Devereaux, A., \& Lobchuk, M. M. (2014). A qualitative investigation of the roles and perspectives of older patients with advanced cancer and their family caregivers in managing pain in the home. BMC palliative care, $13(1), 39$.

Meeker, M. A., Finnell, D., \& Othman, A. K. (2011). Family caregivers and cancer pain management: a review. Journal of family nursing, 17(1), 29-60.

Merlin, J. S., Childers, J., \& Arnold, R. M. (2013). Chronic pain in the outpatient palliative care clinic. American Journal of Hospice and Palliative Medicine, 30(2), 197-203.

Miccinesi, G., Bianchi, E., Brunelli, C., \& Borreani, C. (2012). End-of-life preferences in advanced cancer patients willing to discuss issues surrounding their terminal condition. European journal of cancer care, 21(5), 623-633.

Michna, et al 2014 Systematic Literature review and meta-analysis of the efficacy and safety of prescription opioids, including abuse-deterrent formulations in non cancer pain management

Minozzi, S., Amato, L., \& Davoli, M. (2013). Development of dependence following treatment with opioid analgesics for pain relief: a systematic review. Addiction, 108(4), 688-698.

Morgan, B. D., \& White, D. M. (2009). Managing pain in patients with co-occurring addictive disorders. Journal of Addictions Nursing, 20(1), 41-48.

National Consensus Project for Quality Palliative Care (2013) Retrieved from : http://www.nationalconsensusproject.org/NCP Clinical Practice Guidelines 3rd Editio n.pdf 
Oliver, J., Coggins, C., Compton, P., Hagan, S., Matteliano, D., Stanton, M., ... \& Turner, H. N. (2012). American Society for Pain Management Nursing Position Statement: Pain management in patients with substance use disorders. Pain Management Nursing, 13(3), $169-183$.

ONS (2013). Oncology nursing society position on cancer pain management.

Pade, P. A., Cardon, K. E., Hoffman, R. M., \& Geppert, C. M. (2012). Prescription opioid abuse, chronic pain, and primary care: a Co-occurring Disorders Clinic in the chronic disease model. Journal of substance abuse treatment, 43(4), 446-450.

Payne, S., Turner, M., Seamark, D., Thomas, C., Brearley, S., Wang, X., ... \& Milligan, C. (2014). Managing end of life medications at home - accounts of bereaved family carers: a qualitative interview study. BMJ supportive \& palliative care, bmjspcare-2014.

Pesut, B., \& McDonald, H. (2007). Connecting philosophy and practice: implications of two philosophic approaches to pain for nurses' expert clinical decision making. Nursing Philosophy, 8(4), 256-263.

Petrakis, I. L., Rosenheck, R., \& Desai, R. (2011). Substance use comorbidity among veterans with posttraumatic stress disorder and other psychiatric illness. The American journal on addictions, 20(3), 185-189.

Reed, S. (2010). A unitary-caring conceptual model for advanced practice nursing in palliative care. Holistic Nursing Practice, 24(1), 23-34. doi:10.1097/HNP.0b013e3181c8e4c7

Reid, C. M., Gooberman-Hill, R., \& Hanks, G. W. (2008). Opioid analgesics for cancer pain: symptom control for the living or comfort for the dying? A qualitative study to 
investigate the factors influencing the decision to accept morphine for pain caused by cancer. Annals of Oncology, 19(1), 44-48.

Reynolds, J., Drew, D., \& Dunwoody, C. (2013). American Society for pain management nursing position statement: pain management at the end of life. Pain Management Nursing, 14(3), 172-175.

Riesenberg, L., \& Justice, E. M. (2014). Conducting a successful systematic review of the literature, part 1. Nursing, 44(4), 13-17. doi:10.1097/01.NURSE.0000444728.68018.ac

Rigg, K. K., \& Murphy, J. W. (2013). Understanding the Etiology of Prescription Opioid Abuse Implications for Prevention and Treatment. Qualitative health research, 1049732313488837.

Robert, C. , Wilson, C. , Donnadieu, S. , Gaudy, J. , \& Arreto, C. (2010). Evolution of the scientific literature on pain from 1976 to 2007. Pain Medicine, 11(5), 670-684.

Roe, B., Beynon, C., Pickering, L., \& Duffy, P. (2010). Experiences of drug use and ageing: health, quality of life, relationship and service implications. Journal of Advanced Nursing, 66(9), 1968-1979.

Running, A., \& Turnbeaugh, E. (2011). Oncology Pain and Complementary Therapy. Clinical Journal Of Oncology Nursing, 15(4), 374-379. doi:10.1188/11.CJON.374-379

Sandelowski, M., \& Barroso, J. (2007). Handbook for synthesizing qualitative research. Springer Publishing Company.

Sandelowski, M., \& Leeman, J. (2012). Writing usable qualitative health research findings. Qualitative Health Research, 22(10), 1404-1413. 
Saunders, C. (1976) Retrieved from :

http://www.cancer.org/treatment/findingandpayingfortreatment/choosingyourtreatmenttea m/hospicecare/hospice-care-hospice-care

Savage, S. R., Kirsh, K. L., \& Passik, S. D. (2008). Challenges in using opioids to treat pain in persons with substance use disorders. Addiction science \& clinical practice, 4(2), 4

Schneider, J. P., \& Kirsh, K. L. (2010). Defining clinical issues around tolerance, hyperalgesia, and addiction: a quantitative and qualitative outcome study of long-term opioids dosing in a chronic pain practice. J Opioids Manag, 6(6), 385-95

Shugarman, L. R., Goebel, J. R., Lanto, A., Asch, S. M., Sherbourne, C. D., Lee, M. L., ... \& Lorenz, K. A. (2010). Nursing staff, patient, and environmental factors associated with accurate pain assessment. Journal of pain and symptom management, 40(5), 723-733.

Simone, C. B., II, N. V., Hampshire, M. K., \& Metz, J. M. (2012). Cancer Patient Attitudes Towards Analgesic Utilization and Pain Intervention. The Clinical journal of pain, 28(2), 157.

Smith, P., Schofield, P., Aveyard, B., \& Black, C. (2007). Controversies surrounding the management of pain in patients with terminal cancer. JOURNAL OF COMMUNITY NURSING, 21(10), 4.

Spitz, A., Moore, A. A., Papaleontiou, M., Granieri, E., Turner, B. J., \& Reid, M. C. (2011). Primary care providers' perspective on prescribing opioids to older adults with chronic non-cancer pain: a qualitative study. BMC geriatrics, $11(1), 35$.

Starr, T. D., Rogak, L. J., \& Passik, S. D. (2010). Substance abuse in cancer pain. Current pain and headache reports, 14(4), 268-275. 
Substance Abuse and Mental Health Services Administration, Results from the 2013 National Survey on Drug Use and Health: Summary of National Findings, NSUDUH Series H-48. Rockville, MD:Substance Abuse and Mental Health Services Administration, 2014

Sullivan, M. D., \& Howe, C. Q. (2013). Opioid therapy for chronic pain in the United States: promises and perils. PAIN®, 154, S94-S100.

St. Marie, B. (2013). Coexisting addiction and pain in people receiving methadone for addiction. Western journal of nursing research, 0193945913495315.

St Marie, B. (2014). Health Care Experiences when Pain and Substance Use Disorder Coexist:“Just Because I'm an Addict Doesn't Mean I Don't Have Pain”. Pain Medicine, 15(12), 2075-2086.

Tanner, C. A., Benner, P., Chesla, C., \& Gordon, D. R. (1993). The phenomenology of knowing the patient. Image: The Journal of Nursing Scholarship, 25(4), 273-280.

Tracy, S. M., \& DiNapoli, P. P. (2012). Exploring the Theory of Integral Nursing with Implications for Pain Management Practice. International Journal For Human Caring, $16(1), 26-33$.

Upshur, C. C., Bacigalupe, G., \& Luckmann, R. (2010). “They don't want anything to do with you": Patient views of primary care management of chronic pain. Pain Medicine, 11(12), 1791-1798.

Wachholtz, A., Foster, S., \& Cheatle, M. (2015). Psychophysiology of pain and opioid use: Implications for managing pain in patients with an opioid use disorder. Drug and alcohol dependence, 146, 1-6. 
Walsh, A. F., \& Broglio, K. (2010). Pain management in advanced illness and comorbid substance use disorder. Journal of Hospice \& Palliative Nursing, 12(1), 8-14.

Walley, A.Y. \& Roll, F.J. (2007). Principles of caring for alcohol and drug users. In T.E. King \& M.B. Wheeler (Eds), Medical management of vulnerable and underserved patients: principles, practice and populations (341-350). New York, NY: McGraw Hill.

Watson, C. P. N. (2012). Opioids in chronic noncancer pain: More faces from the crowd. Pain Research \& Management: The Journal of the Canadian Pain Society, 17(4), 263.

Webber, K., Davies, A. N., \& Cowie, M. R. (2011). Breakthrough pain: a qualitative study involving patients with advanced cancer. Supportive Care in Cancer, 19(12), 2041-2046.

Wilson, B. (2007). Nurses' knowledge of pain. Journal of Clinical Nursing, 16(6), 1012-1020.

Wilson, B. (2009). Can patient lifestyle influence the management of pain?. Journal of clinical nursing, 18(3), 399-408.

Wilson, E. , Morbey, H. , Brown, J. , Payne, S. , Seale, C. , et al. (2015). Administering anticipatory medications in end-of-life care: A qualitative study of nursing practice in the community and in nursing homes. Palliative Medicine, 29(1), 60-70.

Wohleber, A. , McKitrick, D. , \& Davis, S. (2012). Designing research with hospice and palliative care populations. American Journal of Hospice and Palliative Medicine, 29(5), $335-345$.

Wu, H. L., \& Volker, D. L. (2009). The use of theory in qualitative approaches to research: application in end-of-life studies. Journal of advanced nursing, 65(12), 2719-2732.

Yanni, L. M., McKinney-Ketchum, J. L., Harrington, S. B., Huynh, C., Amin, BS, S., Matsuyama, R., ... \& Garufi-Clark, L. (2010). Preparation, confidence, and attitudes 
about chronic noncancer pain in graduate medical education. Journal of graduate medical education, 2(2), 260-268.

Zanini, C., Sarzi-Puttini, P., Atzeni, F., Di Franco, M., \& Rubinelli, S. (2014). Doctors' Insights into the Patient Perspective: A Qualitative Study in the Field of Chronic Pain. BioMed Research International, 2014, 514230. doi:10.1155/2014/514230

Zerzan, J., Lee, C. A., Haverhals, L. M., \& Nowels, C. T. (2011). Exploring physician decisions about end-of-life opiate prescribing: a qualitative study. Journal of palliative medicine, 14(5), 567-572.

Zolnierek, C. D. (2014). An Integrative Review of Knowing the Patient. Journal of Nursing Scholarship, 46(1), 3-10. 